\title{
Impacts of COVID-19 on Sustainable Development Goals and effective approaches to maneuver them in the post-pandemic environment
}

\author{
Rajvikram Madurai Elavarasan ${ }^{1} \cdot$ Rishi Pugazhendhi $^{2} \cdot$ G. M. Shafiullah ${ }^{3} \cdot$ Nallapaneni Manoj Kumar $^{4}$. \\ Mohammad Taufiqul Arif ${ }^{5} \cdot$ Taskin Jamal $^{6} \cdot$ Shauhrat Singh Chopra ${ }^{4} \cdot$ Joanna Dyduch $^{7}$
}

Received: 9 August 2021 / Accepted: 23 November 2021 / Published online: 15 January 2022

(c) The Author(s), under exclusive licence to Springer-Verlag GmbH Germany, part of Springer Nature 2022

\begin{abstract}
In the pursuit of constructing a sustainable world for all through the instrumental seventeen Sustainable Development Goals, the COVID-19 pandemic emerged and affected the efforts concentrated on these goals. Therefore, there is a pressing need to analyze the extent of the impact that unfolded from the pandemic on each Sustainable Development Goal and further to direct the post-pandemic situation to accelerate the progress in every goal. Besides, there exists a knowledge gap in understanding the Sustainable Development Goals and its interaction with each goal through synergic and trade-off effects. To address the aforementioned imperative problems, this study is formulated to perform an impact assessment as well as to provide direction in the post-pandemic environment to effectively progress towards the Sustainable Development Goals by using a hybrid qualitative and quantitative framework. A detailed investigation is carried out to examine the pandemic impacts in every goal, and a quantified impact analysis is performed in terms of the targets of the Sustainable Development Goals with the aid of ranking methodology. The results indicate that SDG 1 and SDG 8 are the most impacted goal. To provide deeper perspectives into the Sustainable Development Goals, a critical analysis of the targets and indicators is performed to characterize the goals from their elemental point of view, such as nature of goals, depending factors, locus of the goal, and Sustainable Development Goal interactions. Further, a novel parameter, the degree of randomness, is proposed whose application in environmental research is immense. The impact on each goal and impact interaction between all the SDGs are also mapped, through which the dynamics of Sustainable Development Goal interactions is elaborated. In context with the post-pandemic scenario, the strategies to achieve the Sustainable Development Goals with environmental focus are presented with prioritization factor that supports quick recovery. The introduced prioritization factor is formulated by employing a multi-criteria analysis methodology. In addition, the fundamental elements of SDGs are built upon one another to frame an optimized and effective approach to achieving the SDGs in the post-pandemic environment. Despite the strategies, a conceptual framework to align the business practices with the SDGs is propounded. This study deep down would provide a unique perspective to the research community and would impart deeper knowledge in connection with sustainability, while the solutions framed would steer the policy and decision-makers.
\end{abstract}

Keywords Sustainable Development Goals (SDGs) · COVID-19 pandemic · Environmental sustainability · SDG interaction · Degree of randomness

\section{Introduction}

The pandemic resulted from the novel coronavirus has caused a global crisis and affected people physically, mentally, and economically. This pandemic will prevail in the memories of generations of people, and unfortunately, the

Responsible Editor: Lotfi Aleya

Rajvikram Madurai Elavarasan

rajvikram787@gmail.com

Extended author information available on the last page of the article impact caused by the pandemic cannot be erased by any sort of rapid remedies. The whole world realigned itself to fight the COVID-19, and the key elements of the society, especially the government, healthcare system, industries, and the 
public, contributed their joint efforts to achieve the common goal of mitigating the spread and ultimately to eliminate the coronavirus even if it leads to a consequential impact in terms of economic crisis. From another perspective, the cataclysm impact made by the pandemic crisis need to be assessed, and proper measures should be implemented so that humanity can thrive with minimal impact in the postpandemic scenarios.

The seventeen Sustainable Development Goals (SDGs) supported by 169 targets were adopted in the historic UN summit in September 2015 for guiding the development that needs to take place in the next 15 years (from 2015) and thus, giving rise to a sustainable world for all (UN SDGs 2020; UNDP 2020). Each SDG is not an independent goal, that is, an advancement made in any goal may effectuate synergic or trade-off effect with the progress in other goals. As every possibility for constructing a better world is being analyzed, engineered, and managed, the emerged unexpected enemy is influencing the multifold factors questioning the progress of SDGs. The prevalence of COVID-19 pandemic inflicted a distinctive drag on the progress of these superior goals. This consequential drag might either accelerate the progress by overcoming specific challenges or slacken the pace of progression by creating much more challenges to resolve. Thus, understanding the interaction between the SDGs is crucial, and knowing how the impact can reverberate across multiple goals would help us to resolve any similar problems in the near future. From another perspective, the pandemic can be considered an opportunity for addressing SDG key challenges by exploring the changes that happened in the stipulated time, and such an approach can remap the pathway towards achieving SDGs. In context with this, analyzing the impacts on each goal is vital, and subsequent planning and effective execution of the best possible efforts as a revitalization strategy in the post-pandemic world is utmost which in the fullness of the time would sail us towards sustainability.

Wang and Huang (2021) performed a meta-analysis and sorted out that the COVID-19 pandemic has a negative influence on 17 SDGs, while it has a positive influence on 14 SDGs. Another study by Tonne (2021) demonstrates that COVID-19 highlights the fragilities in society and human development and envisions the situation to make better decisions towards sustainability. The impacts of COVID-19 on the socio-economic, energy-environment, transport sector, and SDGs are presented by Nundy et al. (2021). The study suggests that in the course of recovering from the pandemicinfluenced impacts, the progress towards SDGs might even become worse and recommends collaborative efforts to progress towards sustainability. Jaiswal and Jayakumar (2021) summarized the pros and cons of the changes induced by the COVID-19 pandemic as well as elucidated the lessons derived from the pandemic crisis. A study focuses on mapping the impacts of the COVID-19 pandemic on energyand environment-related SDGs (i.e., SDGs 7, 9, and 13) by using the Analytic Hierarchy Process (AHP) methodology. The results highlight a net positive impact on SDG 7, stagnant progress on SDG 9, and a negative impact on SDG 13 (Fulzele et al. 2021). Fenner and Cernev (2021) discussed the implications of COVID-19 on SDGs $1,3,13,14$, and 15 which is regarded as "foundational" goals. Further, the study analyzes the future recovery pathways, and by utilizing scenario analysis, the recovery pathways are categorized into four scenarios: (i) prioritization of global well-being, (ii) recovery focused on world trade, (iii) widened poverty gaps, and (iv) earth systems in danger. Zhou and Moinuddin (2021) proposed and utilized an SDG interlinkage analysis for assessing the COVID-19 impacts and its recovery on two Asian countries, the Republic of Korea and Bangladesh. The study suggests that by stimulating the progress in the impacted SDGs in the post-pandemic period, the SDGs can be put back on track, but focusing on affected SDGs alone might aggravate the trade-off that exists with environmental goals. Therefore, the stimulating efforts for managing the pandemic impacts should be inclusive of environmental goals.

The impact of COVID-19 is exacerbated in developing countries, and a study illustrates such impacts by considering Nigeria as a case study (Fagbemi 2021). The measures to curb the impacts emanated from the pandemic will likely lead to overlooking of critical issues prevailing in developing countries, such as infrastructural deficiencies, conflicts, paucity of quality education, fragile fiscal space, weak institutions, and inequalities. A review study emphasizes the pandemic impact on food security, agriculture, and livelihoods from the perspectives of developing countries and also provides coping strategies for the post-pandemic period (Workie et al. 2020). Another review study is propounded to investigate the impacts of COVID-19 on the triple bottom line of sustainability as well as on social, economic, and environment (Ranjbari et al. 2021). The study also emphasizes a sustainability action plan inclusive of pandemic impacts, sustainability transition during recovery with a special focus on SDG 9 and SDG 12, innovative approaches to substantiate economic resilience, investigation of longterm effects on social sustainability, and harmonization of COVID-19 studies germane to sustainability research.

From the literature review, it can be observed that only specific explicit impacts on SDGs are covered in most impact assessment studies, while a holistic examination of impacts on all the SDGs is not discussed in any of the studies. Furthermore, the inference and key trends extracted from the impact assessment are not directed to frame the post-pandemic strategies. The knowledge on SDGs and the utilization of SDG interaction are often overlooked in the scientific literatures which should be prioritized in strategic 
planning. These knowledge gaps are well addressed in this study. The proposed study investigates the various impacts on the individual goals caused by the pandemic and also provides an insight into how the impact on one goal affects the other, altogether mapping an impact nexus between the 17 SDGs. This study also emphasizes the SDG knowledge in coordinating strategies that are required to tackle the pandemic-induced impact. Besides, a direction is provided to effectively approach the SDGs in the post-pandemic world. The novelty of this work is in:

- Examining a detailed outlook on the impact resulted in each SDGs and quantifying them in terms of each target to obtain a cumulative and comprehensive impact assessment on SDGs.

- Characterizing the SDGs based on nature of goals, depending factors, sensitive dependency factor, locus of goal, and SDG interaction. A novel parameter is also derived to determine the effectiveness of the efforts implemented in a goal.

- Analyzing the degree of influence between the goals and in mapping the SDGs impact interactions.

- Assessing the post-pandemic strategies with the prioritization factor through multi-criteria analysis.

- Designing a conceptual approach to increase the effectiveness for implementing post-pandemic strategies and align the business practices with the SDGs.

\section{Research framework}

To perform research in the domain of sustainability, a proper framework is utmost. This study includes numerous methodologies carved into a single framework to achieve four main outcomes: (i) assess the impacts on SDGs and quantify them, (ii) understand the SDG interactions, (iii) propose strategies and examine them for prioritization, and (iv) determine the

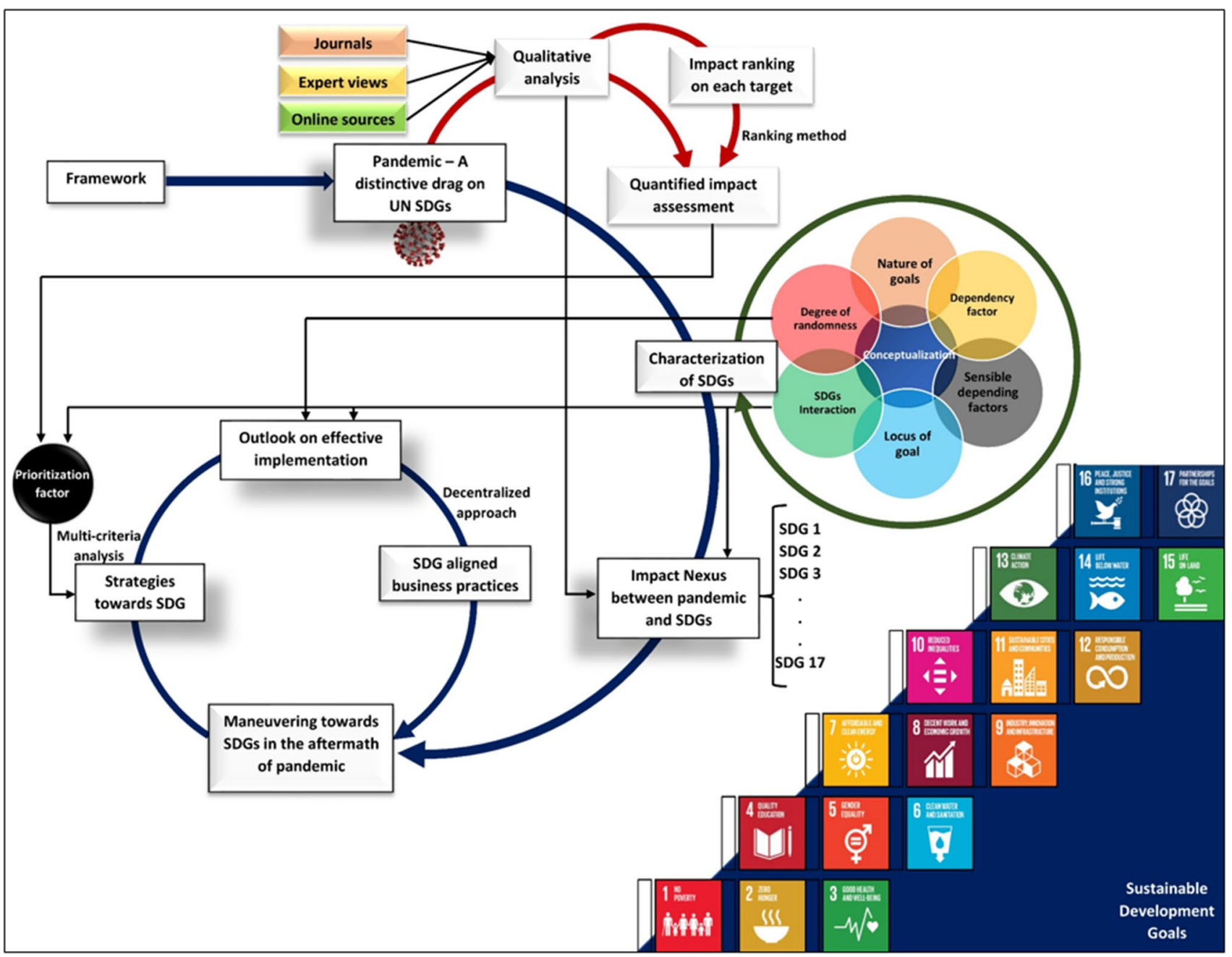

Fig. 1 Framework of the proposed study 
effective approach. The section-wise framework of this study is graphically depicted in Fig. 1.

Investigation of the pandemic impacts on SDGs is accomplished by extensive literature review from journals and online sources. Also, expert views are considered in impact assessment. In order to quantify the impacts, a simple ranking method is utilized to quantify the intensity of impact on each target of the goal. Finally, cumulative impact scores on every goal are obtained to elucidate the net influence that pandemic has caused on the SDG progress. From the various targets and indicators of each SDG, a basic classification and characterization of goals is performed, which is underpinned by critical interpretation and qualitative analysis. With the entrenched characterization, deeper insights on SDGs are established, while a new parameter namely, degree of randomness, is proposed by the authors to analyze the uncertainties in the pathways to achieve the intended objectives of the goal. Altogether, the conceptualized understandings of SDGs are built upon one another to obtain the big picture of SDG interaction, and the pandemic impact is presented as a case study to showcase the SDG interaction pathways.

After a comprehensive impact assessment and insights on SDG interaction, the study moves forward to propose coping strategies to revitalize the pandemicinduced impacts as well as to direct humanity towards sustainability. The strategies are framed by investigating the studies dealing with sustainability and are blended with the authors' contributions. The nuance of this study relies on using the SDG interaction and the impact assessment in evaluating the proposed strategies to identify the effective strategies whose role is immense in addressing the impact as well as promoting sustainability. For which, authors introduce a new evaluation factor, namely, prioritization factor, and this factor is determined with the aid of multi-criteria analysis. This multi-criteria analysis takes into account of SDG interaction in context with synergic and tradeoff effects between the goals, while it also allocates prioritization score based on the degree of remedy that a strategy offers to the highly impacted goals. The study further extends the contribution by analyzing effective ways to implement the strategies. This is accomplished by merging the concepts of prioritization factor, SDG interaction, and degree of randomness. In addition, the conceptual framework is developed for aligning the business practices with SDGs by analyzing the business structure combined with a literature review. This framework is based on a decentralized approach. Altogether, the proposed study performs a qualitative, quantitative, and critical analysis on SDGs to map the impacts and direct the proposed strategies to effectively support humanity.

\section{Pandemic - a distinctive drag on UN Sustainable Development Goals}

In this section, the discussion is presented concerning the various progress, impact, and challenges encountered by the SDGs in line with the pandemic, accompanied by a clear depiction of positive or negative drag experienced by individual goals.

\section{Poverty (SDG 1)}

The primary target of this goal is to achieve a less than $3 \%$ extreme poverty rate at a global level by 2030 (SDGs Knowledge Platform 2020a). Poverty is a multidimensional factor, and numerous studies also represent the intense interdependence between poverty and other factors (Dhahri and Omri 2020; Schleicher et al. 2018). According to a study by Robles Aguilar and Sumner, the young people residing in rural areas, although not working necessarily in agriculture, are largely considered the world's multidimensionally poor (Aguilar and Sumner 2020). Hence, specific attention is required in the case of multidimensional poverty control and poverty among children (Pinilla-Roncancio et al. 2020; Pac et al. 2020). Indirect ways of mitigating poverty are also been investigated, such as co-benefits of the Paris Agreement on poverty (Campagnolo and Davide 2019).

In the period between 2015 and 2018, the rate of poverty reduction slowed down to less than $0.5 \%$ per year (The World Bank 2020). However, due to the devastating impact of COVID-19, the poverty rate will shoot up for the first time since 1998. The people belonging to congested urban livings, involved in informal services and manufacturing and those heavily affected by lockdowns as well as mobility restrictions are more prone to attain poverty than the chronic poor. The longevity of the pandemic occurrence and the economic recovery rate will influence the severity of these effects.

UN Development Programme (UNDP) conducted a new study to assess the recovery poverty trajectories in the post-COVID future (UNDP SDG Integration 2020). The analysis is underpinned by three scenarios such as "COVID Baseline," "High Damage," and "SDG Push" scenarios and is shown in Fig. 2. The COVID baseline scenario indicates the additional poverty influenced by the pandemic and the subsequent recovery projections. In this scenario, the impact of pandemic results in a raise of 44 million people in extreme poverty (UNDP SDG Integration 2020). The High Damage scenario represents the future in which the economic recovery is slow, and the world might witness an additional staggering 251 million 
Fig. 2 Impact of pandemic on poverty and its projections up to 2050 under various scenarios. Data source: UNDP SDG Integration (2020)

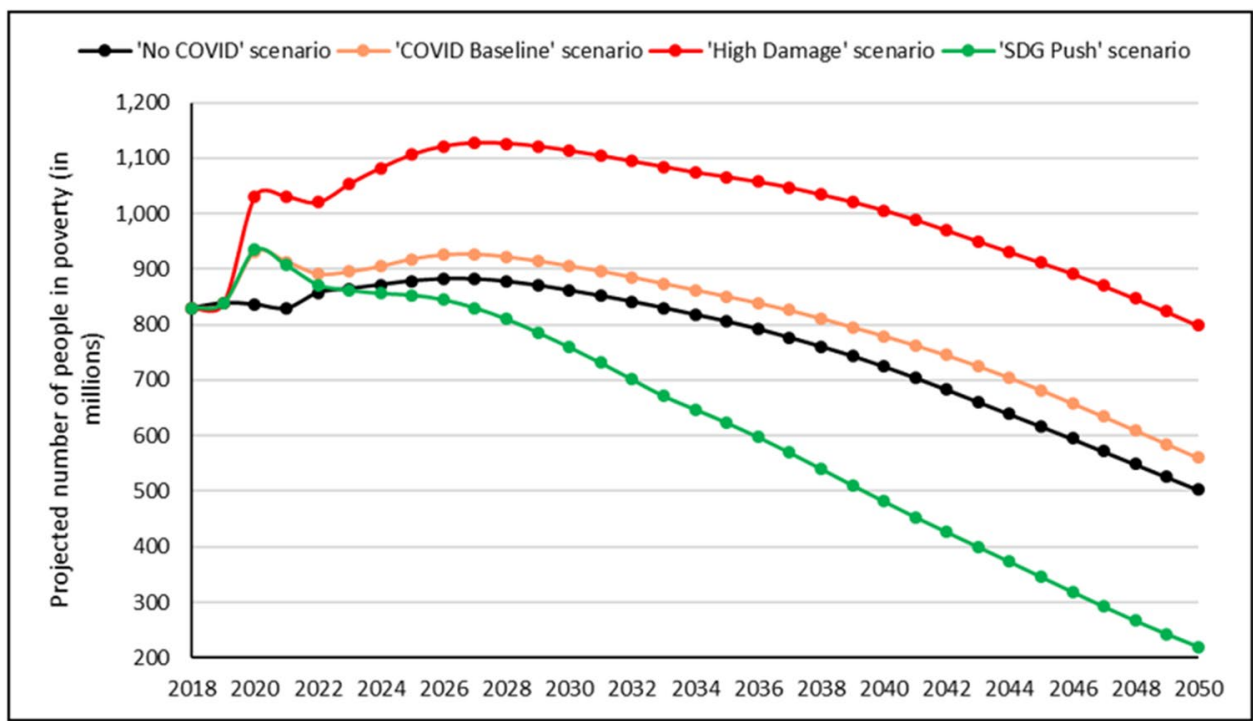

people under the status of extreme poverty, raising the total count above 1 billion (UNDP SDG Integration 2020). The SDG Push scenario highlights the role of targeted policy interventions that focus on accelerating the efforts towards a resilient and green future. This scenario yields promising results to bring down the poverty that are even emerged from the pandemic impact. On the other hand, the low- and middle-income countries suffer to a greater extent in terms of poverty recovery when compared to high-income countries (Jahan and Rahman 2020). Altogether, it can be inferred that if humans fail to follow the roadmap to achieve SDGs, then the pandemic-influenced impact on poverty would prevail for a decade at the least.

\section{Hunger (SDG 2)}

The main motto of Goal 2 is to end hunger and, simultaneously, attain food security and promote sustainable agriculture. Regarding the recent progress, it is concerning that the undernourished rate is rising for three consecutive years after a prolonged decline (SDGs Knowledge Platform 2020b).

The impact of COVID-19 on Goal 2 occurs indirectly. Society is in demand for food; as usual, the production levels of staple foods are stable; and only in meeting the demand, the pandemic plays a role directly through supply chain issues among different stages of markets. According to the report, the prices of world agricultural commodity are stable and are expected to continue in 2020 (World Bank Blogs 2020). As people lose their jobs, it makes them vulnerable to poverty which hinders them to purchase their basic needs including food. So, it is clear that the main influence that drags down Goal 2 is poverty, and thus, the goal is affected indirectly. In 2020, due to COVID-19, about additional 132 million people may suffer from undernourishment (UN statistics 2020a). A study highlights that fifteen, ten, six, and four developing countries distributed in Africa, Latin America, Oceania, and Asia, respectively, are most vulnerable to the impacts on the supply of cereals (Udmale et al. 2020). This induces transient food insecurity among these countries. The prime impact on SDG 2 will be the lack of significant focus in the next few years as poverty will emerge as a potential and bigger problem which might amplify the malnutrition levels among children. On analyzing the key strategies to end hunger, a new approach in leadership, adaptive measures towards the agroecosystem diversification, and investments in the agricultural sector are observed to be crucial to achieving the goal (Herrmanna and Rundshagen 2020; Blesh et al. 2019; Mason-D'Croz et al. 2019).

\section{Health and well-being (SDG 3)}

The emergence of COVID-19 affects and strains the healthcare system more straightforwardly than ever which drags SDG 3. The number of infections is rising rapidly, and the healthcare unit all around the world is making a way to provide health support in all forms. Further, the government and the industries act as supporting bodies for the healthcare system during the pandemic (Elavarasan and Pugazhendhi 2020). Currently, the main challenges associated with the COVID-19 and SDG 3 are to tackle the situation and to provide quality healthcare to every individual irrespective of the situation. Only when the pandemic is controlled, the economy can be reshaped or the progress in SDGs can be resumed. A typical approach towards the pandemic is represented in Fig. 3.

Apart from these impacts, the progress that is already taking place is affected in terms of other diseases. For instance, 
Fig. 3 A typical approach towards the pandemic

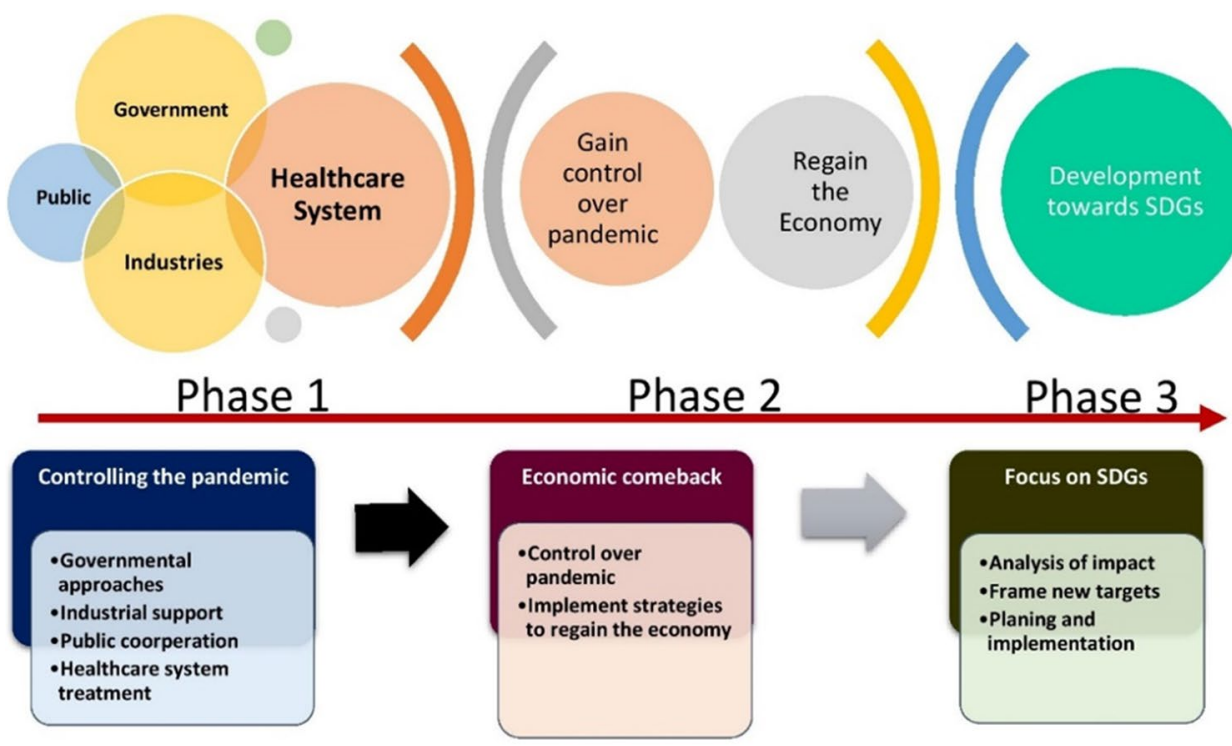

more than 70 countries have stalled the childhood vaccination programs during this crisis (The Lancet Public Health 2020). The healthcare sector's normal functioning for providing service to cancer screening, non-COVID infectious diseases, family planning, and promoting health awareness is either interrupted or completely neglected. This may even have years of impact on the populations skipping these services, and it can wipe out the years of progress achieved by consistent health and nutritional services (Khetrapal and Bhatia 2020). According to a recent study, the deaths of children per month under the age of 5 would witness a rise of 9.8 to $44.8 \%$, and an increase of 8.3 to $38.6 \%$ in maternal deaths per month would result over 6 months if the routine health services and access to food are disrupted (UN statistics 2020b). On the other hand, the indirect health impacts inflicted by the loss of income, poorer nutrition, and disruption of continuing medical care could be humungous, and the extent of the indirect impact is highly uncertain (Hughes et al. 2021).

In the post-pandemic period, the role of spending towards the progress of SDG 3 is significant, and more funds are needed to be allocated for improving the health sector especially in low-income and lower-middle-income countries. Meanwhile, a study claims that domestic resource mobilization is the key to generating sources for SDG 3 (Sundewall and Forsberg 2020).

\section{Quality education (SDG 4)}

Education is influenced by several social factors such as education policies, teacher's ability, parents, civil society, and politics. Feasible analysis of these factors can help us to reform the educational approaches towards SDG 4. Barbara et al. have performed one such analysis on the politics of quality reforms and presented the challenges associated with attaining quality education (Bruns et al. 2019), while another study maps the field of responsible management education in line with SDGs (Storey et al. 2017).

In this pandemic, the global wide closure of educational institutes impacted about $70 \%$ of the world's student population (UNESCO 2020a). The whole education system is backed up with the technology that allows the students with internet accessibility to gain their knowledge. On the other hand, internet facilities are not accessible in every part of the world. Figure 4 shows the internet penetration rate distributed throughout various geographical regions as of 2020 quarter 1 (Internet World Stats 2020). From the figure, it can be observed that the world average is just $58.7 \%$ and the remaining population has to wait to continue their education until the pandemic disappears.

The exposure to distant learning methodology is enough to create an impact on the field of education, and it might have a positive drag on SDG 4 in upcoming years. A study from UNESCO indicates that the cost of achieving SDG 4 has already increased before COVID-19, but given the impacts of the pandemic, the cost has further increased (UNESDOC Digital Library 2020). The cumulative finance needed in the next decade (up to 2030) costs around US\$ 335 billion owing to the need for additional capital for remediation, re-enrollment, second chance programs, and infrastructure requirements which overall caused a net increase of US\$ 205 billion as compared to the normal situation (UNESDOC Digital Library 2020).

\section{Social equalities (SDGs 5 and 10)}

Social equalities imply equalities within and among the societies which include gender equality, anti-racism, income 
Fig. 4 World Internet penetration rate across different geographical regions in quarter 1 of 2020

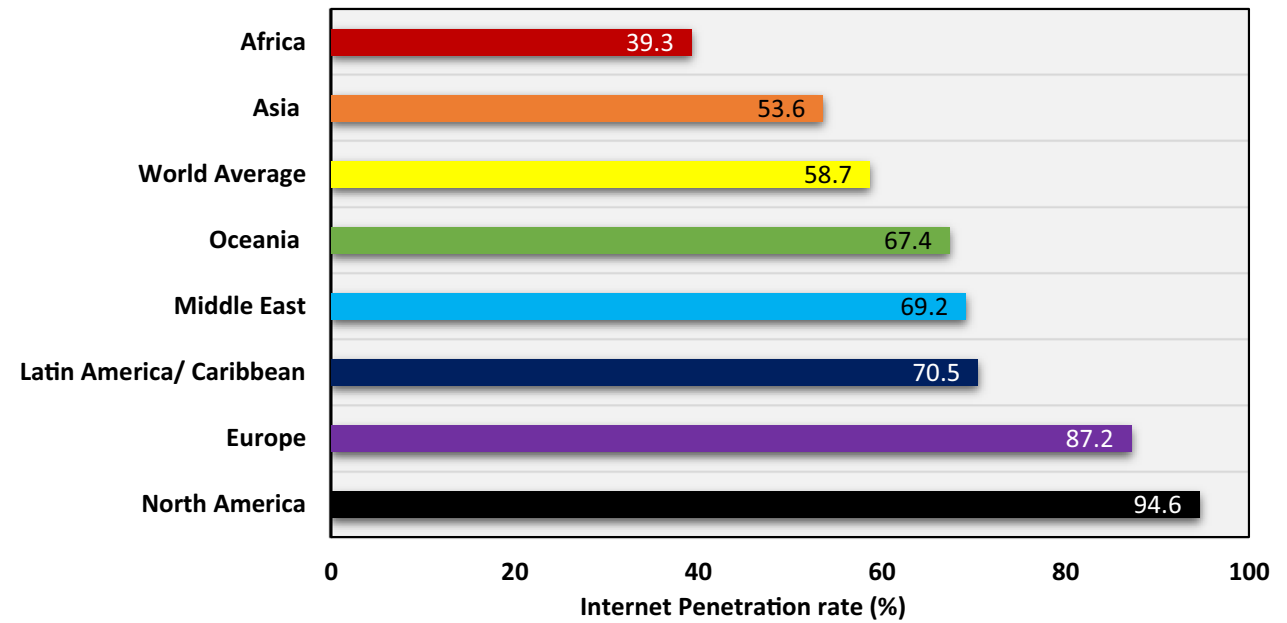

equality, and equal participation in societal activities and decision-making which covers both the SDGs 5 and 10. The relationship between SDG 5 and 10 is depicted in Fig. 5. The UN strategies do not focus on the inequalities in water access and social mobility, but some studies have reported ways to reduce such inequalities as well (Cetrulo et al. 2020; Hackl 2018). It is seen that though the women employment is increasing day by day which is a good progress as in the case of SDG 5, their income is not justifying as compared to a man with a similar performance (not in all the cases) (UNESCO Inclusive Policy Lab 2020a) which in turn contrasts the development in both SDGs 5 and 10. Such complexities exist in strategically dealing with the progress of these goals, and to encounter this problem, the awareness and the governmental schemes and policies should appeal in such a way that it adores the perspective of social equalities.

Concerning the pandemic, the inequalities have played a role in directing the impact. For example, a report mentions that in the USA, blacks are dying at a rate faster than whites (UNESCO Inclusive Policy Lab 2020b). Also, resource-poor countries could not purchase the equipment and products that are desperately required when compared to resourcerich countries. In populous countries like India, urban inequalities exist and the massive population living in slums could not access water (World Resources Institute 2020a). On the other hand, a report claims that the USA experiences wealth inequality, meaning that when some experience a risk, the others (poor wealth) experience a double threat. In addition, the report from the Federal Reserve indicates that about $40 \%$ of Americans could not even cover the emergency expense of $\$ 400$ (Scroll.In 2020).

A clear-cut argument can be made from the impacts; that is, a distressing situation like a pandemic will worsen the impact of inequality than ever. Thus, it can be inferred that the pandemic amplifies the negative drag in the progress of attaining SDGs 5 and 10.

\section{Clean water and sanitation (SDG 6)}

Three in ten people lack access to clean drinking water, and six in ten people lack access to sanitation facilities (Sustainable Development Goals 2021). Wastewater treatment, local governance, policies and services in the water sector, and natural resources are some of the crucial factors that influence the progress of this goal (Herrera 2019; Kookana et al. 2020).
Fig. 5 Relationship between SDG 5 and SDG 10
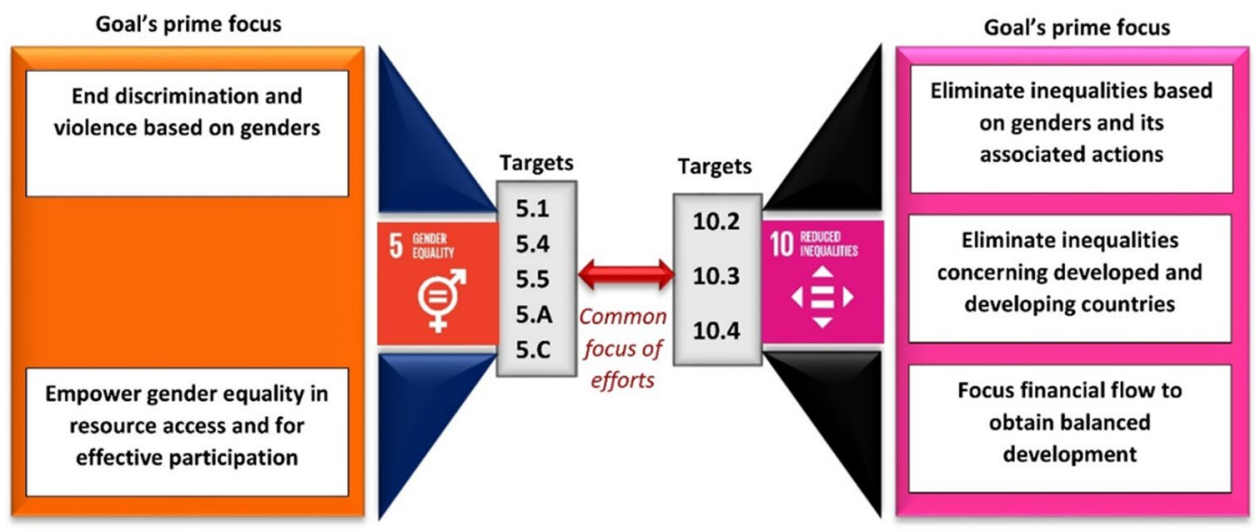
On analyzing the impact of the pandemic on the water crisis, it is clear that the lack of water accessibility to the billions of populations is one of the boosting factors for the prevalence of pandemic. During pandemic, the water pollution levels were low, while consumption was higher due to hygiene requirements. These environmental benefits were achieved at the cost of socio-economic impact which is undesirable. Hence, this calls for integrated management of water, energy, and food for sustainable management of resources, especially in urban areas (Tayal and Singh 2021). For controlling the pandemic, hand sanitizing measures and frequent hand washing have led to an increase in water consumption as well as the generation of waste water has increased multifold. A study shows that water utilities have a significant impact on revenues from industrial and commercials that utilizes the water (International Finance Corporation 2020). It is estimated that on average, $27 \%$ of industrial water demand will fall due to COVID-19 (International Finance Corporation 2020). This is primarily ascribed to a temporary halt in industrial operations. The major impact of SDG 6 in terms of the water and sanitation sector is that the ability to make the critical capital investment was affected drastically. This would create a significant delay in the implementation of projects to improve water security. To tackle this, investments to protect water-related ecosystems is needed, and effective management of the water usage pattern is pivotal (World Resources Institute 2020b).

\section{Affordable and clean energy (SDG 7)}

This goal emphasizes affordable, sustainable, reliable, and modern energy for all. The global electrification rate is accelerating, and it reached $89 \%$ in 2017 , but still, there are 800 million people without access to electricity (SDGs Knowledge Platform 2020c). The renewable energy usage from 2010 to 2019 has been doubled according to the IRENA report (IRENA 2020a).

The construction of new facilities and infrastructure related to the energy sector has been significantly delayed or stopped due to supply chain disruption (Janardhanan et al. 2021). In India alone, the project of extending a $3000 \mathrm{MW}$ power generation capacity through solar and wind energybased projects has been delayed owing to the pandemic ( $p v$ magazine 2020). Also, regular maintenance activity has been limited to a minimum, and priorities are given to repair and restoration only. On the other hand, defaults in the payment of energy utility bills have generated a financial debt among the energy communities.

The SDG 7 closely progresses with SDG 8 and SDG 9. For instance, energy-related commodities such as oils, gases, and petroleum products have drastically affected in terms of price during the pandemic. The demand for crude oil and variation in the spot price of WTI (West Texas intermediate) in US dollars per barrel from December 2019 to November 2020 is depicted in Fig. 6. In February, the WTI spot price had declined nearly by half with a constant decline, and it attained the lowest price ever in mid-March $(\$ 16.55 /$ barrel WTI spot price) (Opendatasoft Data Network 2020). Though the prices are down, the corresponding effect on the cost of petroleum products at the consumer end was not proportional due to future market uncertainties (Kevin et al. 2020). Besides, the countries that depend on the export of crude oil have a pronounced effect on their economy for the short term at least up to the end of 2020.

On analyzing the energy usage pattern during the pandemic, a reduction in power consumption has resulted. The peak power demand dropped 3-4\% in Italy. The energy demand in the USA, India, Singapore, Australia, and China were reduced by $5.7 \%, 26 \%, 8 \%, 6.7 \%$, and $7.8 \%$, respectively (Madurai Elavarasan et al. 2020). Off-grid and
Fig. 6 Variation of oil prices during pandemic

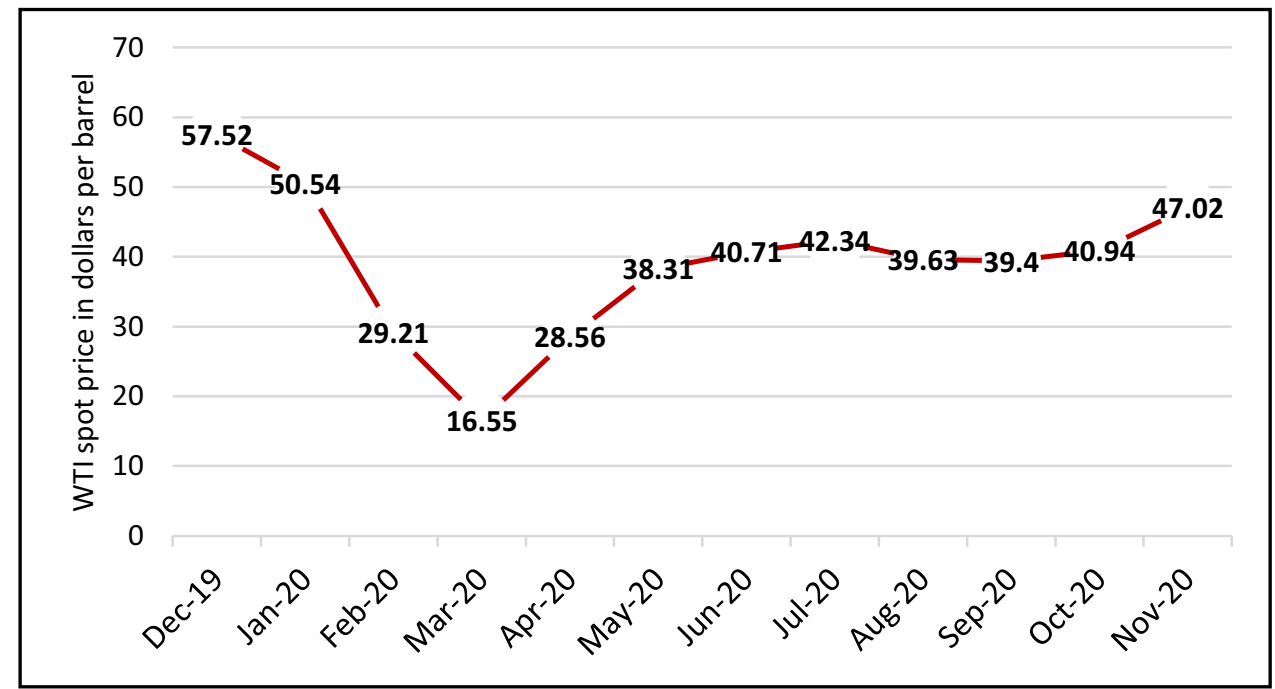


mini-grid companies are facing financial issues and may even risk insolvency.

Concerning clean cooking, a survey of over 100 enterprises reported that two-thirds possess high concerns for the reduced paying ability of the customers (United Nations 2020). To promote clean cooking fuels, strong political prioritization and subsequent investments are required.

\section{Socio-economic impact (SDGs 8 and 9)}

SDGs 8 and 9 deal with decent work, economic growth, industry, innovation, and infrastructure. Amidst the pandemic, the economy and industrial activity have been affected to a much higher extent such that it resulted in the worst global economic fallout since the Great Depression in the 1930s. The World Trade Organization (WTO) predicts that world trade would fall by between 13 and 32\% owing to the effects of the pandemic (World Trade Organization 2020). In 2020, the GDP per capita is expected to decline by $4.2 \%$ before it starts to increase in 2021 at the pace of $3.1 \%$. In the least developed countries, the development rate is projected to weaken to $0.8 \%$, while it is expected to increase at a rate of $4.6 \%$ in 2021 (UN statistics 2020c).

Regarding employment, the highest risk of disruption is experienced by daily wage earners, self-employed, and other service-based firms affected by lockdown measures. According to International Labor Organization (ILO), due to the COVID-19 crisis, the forecasted impact shows a $14 \%$ drop in working time, meaning a loss of 400 million jobs in comparison to the fourth quarter of 2019 (International Labor Organization 2020). Lower- and middle-income countries are affected the most, with an estimated average drop in working hours up to $23.3 \%$-equivalent to 240 million jobs in the second quarter of 2020. Moreover, the income in developing nations cuts by $15 \%$ (International Labor Organization 2020). Hence, it is clear that the COVID-19 pandemic has catastrophic effects on the progress of SDG 8 in multiple aspects.

Significant impact is seen in service sectors such as travel and tourism, which needs more time to recover. The pandemic scenario affected the small-scale industries to a larger extent in terms of their recovery period. Since manufacturing industries drive the overall economic growth, a serious impact on the economy is resulted especially in the least developed countries. The aviation industry which boosts economic development had undergone the deepest fall. According to the International Civil Aviation Organization, the estimates as of June 2020 indicate an overall drop in passengers ranging from 2.29 billion to 3.06 billion which results in gross revenue losses between $\$ 302$ billion and $\$ 400$ billion when compared to the normal situation (UN statistics 2020d). In terms of innovations, the pandemic accelerated the $R \& D$ funding in the pharmaceutical industry and emerging technologies such as digital infrastructure, artificial intelligence, and service-based innovations (UN statistics 2020d).

On the other hand, the work from home scenario amidst the pandemic is gaining attention, and it might change the post COVID world to adopt work from home methodology as a new type of employment branch in line with the conventional working scenario. It will have a positive drag on the employment with more sophisticated approaches which ultimately enhances the progress of SDG 8. Digital business is gaining attention among the public, and this pandemic is an opportunity for the customers to use it. Therefore, hastened digitalization might create more employment opportunities in near future.

\section{Sustainable cities, communities, and society (SDGs 11 and 16)}

SDGs 11 and 16 aim at better living conditions for all the people in a sustainable society with a peaceful environment and justice. Substantial progress has been made in improving the living standards of the people, yet numerous cities suffer from issues such as increased slums, poor quality of air, limited access for transportation, and fewer public spaces. A study by Billie Giles-Corti et al. presented a more comprehensive approach in terms of monitoring, benchmarking, and evaluating policies that are directed towards the development of healthy and sustainable cities (Giles-Corti et al. 2019).

Due to the prevalence of pandemic, the cities and society's day-to-day activities are hindered, and the whole society is fighting the pandemic crisis. Despite the lockdown, the power of societal culture and creativity of the people are leveraging the cooperation among the cities and binding different communities to express unity (UNESCO 2020b). In terms of SDG 11, the major impact is seen on the lifestyle of the people. Around 90\% of the COVID-19 cases are reported in urban areas, and this hits the vulnerable the hardest (UN Statistics 2020e).

Concerning SDG 16, the pandemic threatens to exacerbate the fragilities in society. This indirectly affects the peace of the society by amplifying the social insecurities, sufferings, and inequalities. Protest and blames on the various social bodies in different geographical regions amidst the pandemic are the clear depiction of the rupture of justice and peace within society. Besides, trends suggest that lockdown measures induced high homicide rates in Latin American countries, while it is quite opposite in European countries with a reduced rate of violence (UN statistics 2020f). There is also an increased volume of domestic violence throughout various countries such as Singapore, Malaysia, India, Fiji, Samoa, and Russia. This is evident from the increase in call volumes in domestic violence helplines ranging from $33 \%$ to 
doubling during COVID-19 times (United Nations ESCAP 2020).

\section{Sustainable consumption and conservation of resources (SDGs 12, 14, and 15)}

Table 1 gives a rough idea of how material consumption per capita is increasing at an alarming rate. Hence, welldesigned national policy frameworks and cooperation are much needed to impart sustainability in consumption and production patterns (SDGs Knowledge Platform 2020d). Apart from it, a rise in ocean acidification by $26 \%$ is observed in the past 30 years which if continues will result in a devastating impact on marine life and even land degradation is happening at a worrying scale even though the recent year progress has shown a reduction (SDGs Knowledge Platform 2020e, 2020f).

Concerning SDG 12, a large amount of food is lost in the supply chain before reaching the end customer. The upheaval of biomedical waste generation is witnessed during the pandemic, especially the single-use plastic products (such as PPE) (Mallick et al. 2021). Regarding plastic pollution, a study found that there is a strong correlation between COVID-19-affected population and plastic waste footprint. The study further calls for plastic waste management initiatives, strict regulations, human awareness, and plastic waste footprint research (Mallick et al. 2021). The resources consumed to control the pandemic is high in the medical sector, and the prevailing problem of proper disposal of the mask remains a serious task (Singh and Mishra 2021). Moreover, the pandemic has decreased waste recycling and municipal waste generation (Singh and Mishra 2021).

As human activities are the paramount cause for the impact in SDGs 14 and 15, the pandemic does not have much effect on these goals. Instead, the pandemic muffled the human activities which had a positive impact on the progress of SDGs 14 and 15. The effluents discharged from industries as well as human activities involving water bodies have plummeted during the lockdown (Singh and Mishra 2021). As an example, rivers in India such as Ganga and Yamuna have shown improved surface water quality in the

Table 1 Worldwide material consumption (SDGs Knowledge Platform 2020d)

\begin{tabular}{lc}
\hline Year & $\begin{array}{l}\text { Worldwide } \\
\text { material con- } \\
\text { sumption (met- } \\
\text { ric tons) }\end{array}$ \\
\hline 1970 & 27 billion \\
2015 & 87 billion \\
2017 & 92.1 billion \\
If the extraction remains uncontrolled without political action \\
2060 (Expected) & 190 billion \\
\hline
\end{tabular}

lockdown period (Yunus et al. 2020). It can be inferred that the pandemic had given some breathing time for both land and marine resources (Forbes 2020). Hence, the pandemic provides a positive drag in an indirect way towards these goals. However, these positive benefits are transitory until human being adapts to the pandemic.

\section{Climate action (SDG 13)}

This goal influences almost every other goal, and the progress in SDG 9 without progress in SDGs 12 and 15 will result in degrading effects which in turn powers the climate change, hindering the progress in SDG 13. Hence, balancing the contrasting effect between the goals is necessary by keeping SDG 12 (sustainable consumption) as the center of balance (Campbell et al. 2018). Also, individuals should indulge the notion of climate action in their behavior, feelings, and values for effective action (Bouman et al. 2020).

The pandemic has no direct effect on climate action, but it helped in suppressing human activities in terms of lockdown and quarantine, during which nature's replenishment activities occurred with negligible human interventions. This resulted in a significant reduction in the concentrations of $\mathrm{CO}_{2}$ and particulate matter (PM 2.5) levels. For instance, a $30 \%$ drop in air pollution is observed over the Northeast USA (NASA Aura Atmospheric chemistry 2020). Also, countries like China and India have experienced ever achieved carbon and $\mathrm{NO}_{2}$ reduction. Figure 7 shows the level of $\mathrm{NO}_{2}$ reduction in India from March 25 to April 25, 2020 (NASA Aura Atmospheric chemistry 2020). Apart from air pollution, the pandemic resulted in a cleaner beach than ever, reduced marine pollution and environmental noise (Zambrano-Monserrate et al. 2020). Hence, the pandemic boosted the progress towards achieving green Earth, and indeed, it is a positive drag concerning this goal, yet the effect is ephemeral.

\section{Partnerships for the goal (SDG 17)}

The motto behind this goal is to promote the means of implementation through strong global partnerships for overall sustainable development, or in other words, it is a goal meant to expedite the progress in other goals through joint efforts in terms of global partnerships.

The pandemic has caused several impacts, but in regard to SDG 17, the impact can be assessed in two approaches. One aspect can be approached as to how multiple organizations, governments, and industries have put their joint efforts in mitigating the spread within and among societies. The other aspect deals with how the pandemic impacted the existing partnerships among various countries and organizations. For instance, India has agreed to partially ease the export of hydroxychloroquine and paracetamol to the USA and other 
(a)

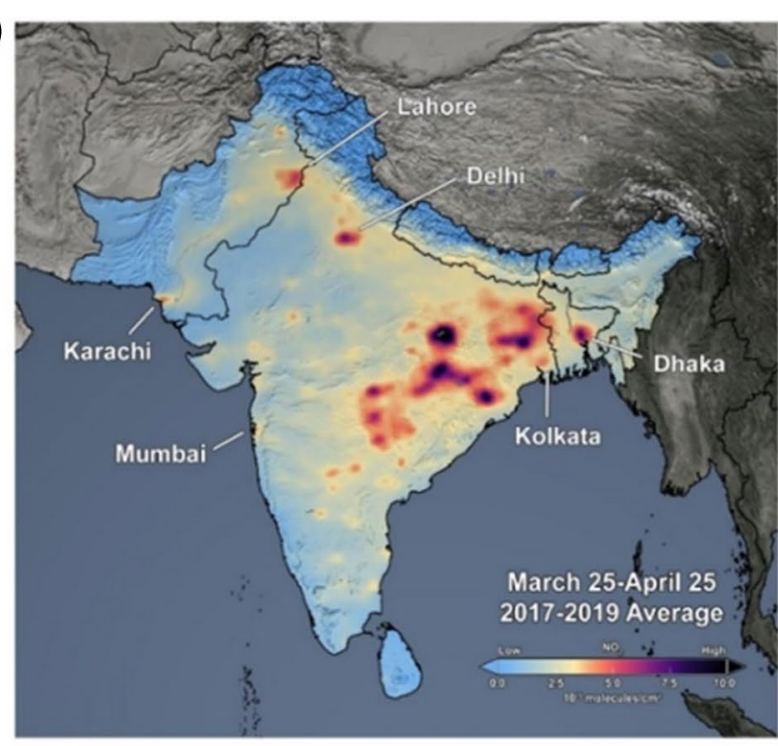

Before Pandemic

(c)

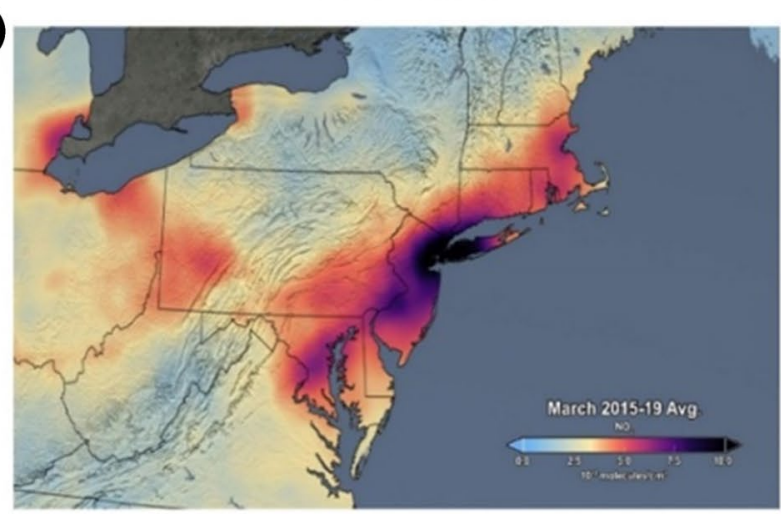

(b)

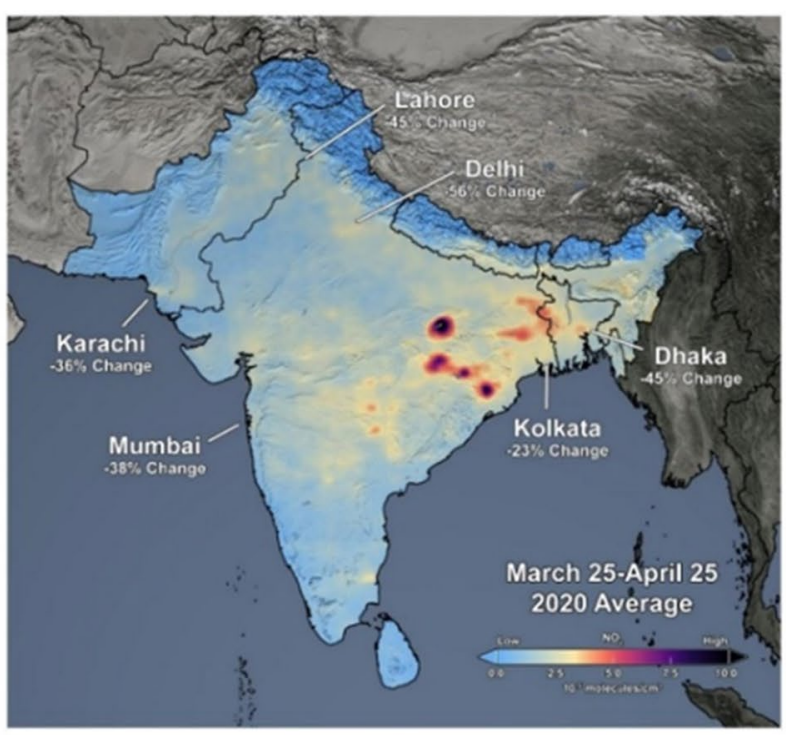

During Pandemic

(d)

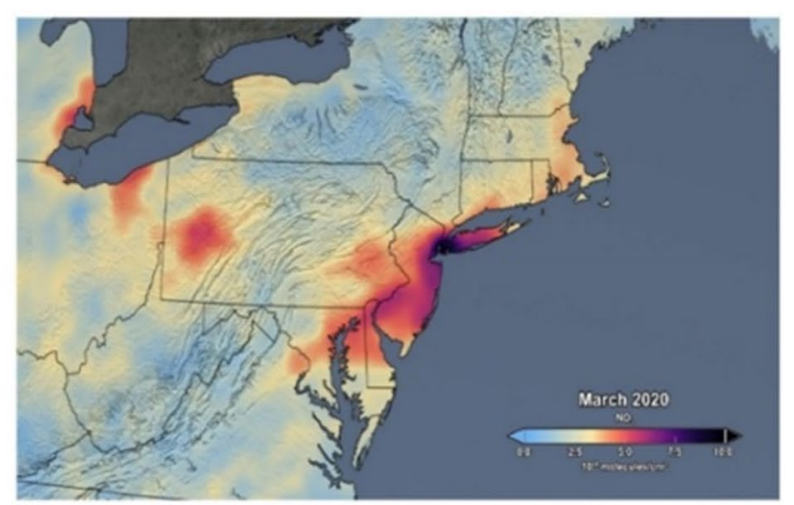

Fig. 7 Impact of pandemic on air quality. a Indian sub-continent—-before pandemic. b Indian sub-continent-during pandemic. c Northeast USA-before pandemic. d Northeast USA—during pandemic (NASA Aura Atmospheric chemistry 2020)

countries, as India is one of the major global producers of hydroxychloroquine (The Print 2020). This was indeed a good gesture among the countries, and it would strengthen their global relationship for near-future needs. Hence, it can be claimed that the new partnerships might have been created and existing partnerships have strengthened. Also, there might be a deterioration among existing partnerships, trade, and foreign direct investments due to the pandemic. Besides the global partnerships, the UN says that trade tensions exist, significant digital divides are experienced, and more importantly, the private investment flows are not in line with sustainable development (GreenBiz 2020). If these challenges are not encountered properly, SDG 17 would not make any sense towards sustainability even though several partnerships exist.

With the pandemic impacts on the economy, the UN Department of Economic and Social Affairs predict a decrease in global remittances of approximately $19.7 \%$ or
$\$ 445$ billion for middle- and low-income countries (RMIT 2020). COVID-19 created an unprecedented scientific race to develop a vaccine and produce it on a global scale. In such a case, partnerships are of utmost, and the COVID-19 Vaccines Global Access (COVAX) initiative demonstrates collaborative efforts among governments, businesses, scientists, society, philanthropists, and global health organizations (RMIT 2020). This partnership among governments is to facilitate the development, production, and equitable distribution of vaccines across the globe, especially in low- and middle-income countries.

\section{Overall COVID-19 pandemic impact analysis on SDGs}

The above sub-sections elaborated the various impacts that dragged the progress in SDGs, but a quantified approach would be much effective in understanding the intensity of impact experienced by each goal. This section frames and 
discusses the impact analysis on SDGs based on the previous section discussion linking with each of 169 targets. A simple ranking method based on weightage is utilized where weightage is allocated to each target by analyzing the possible influence on the progress caused by the pandemic impact. The impact score weightage allocation is based on Table 2.

For a given goal, after quantifying the impact for each target with the help of Table 3, the overall impact score (OIS) of the goal is calculated by using Eq. (1). where $n$ represents the number of targets in the considered goal. The denominator captures the maximum impact situation for the goal. In other words, OIS demonstrates the impact score of the goal with respect to the maximum impact situation. As a result, the OIS will help us to analyze the intensity of impact, and the OIS is distributed between 0 and 1 where 1 represents maximum impact. The OIS of each goal is presented in Table 3.

As a whole, the pandemic ultimately impacted the progress of most of the SDGs. It is clear that SDGs 1

Over all impact score $(O I S)$ of the goal $=\frac{\sum_{i=1}^{n} \text { Impact score of target } \mathrm{i}}{\sum n \times 5}$

and 8 are the most affected goal as the OIS of these goals are 0.69 and 0.55 meaning more than half of the targets in these goals have been highly impacted due to the pandemic. Besides, SDGs 15, 13, and 16 are the least impacted goals, and SDG 14 has a net positive impact due to the pandemic. Hence, significant efforts are needed in addressing the challenges to minimize the impacts on most of these goals.

\section{A deeper interpretation of Sustainable Development Goals}

SDGs are the key to attaining a sustainable world, and thus, understanding the characteristics of the goal is significant for directing our efforts. This section elucidates in-depth concepts of SDGs which is a prerequisite for understanding the upcoming sections.

Nature of goals On analyzing the 17 goals and their targets, it can be observed that a complex relationship exists between each other. Generally, when deducing how each goal can be attained, the nature of the goals can be segregated as implementation-based and consequence-based. Implementationbased goal means that the advancement related to the goal is possible only by implementing certain measures, while consequence-based goals cannot be attained by direct implementation of any strategies but can be only achieved as a function of reaction to a few or many activities.

Depending factor The depending factor is another fundamental parameter that depicts the factor that a goal depends on, and it is derived by analyzing the goal and its corresponding targets. The depending factor for implementationbased goals should be viewed as what developments has to be made to achieve the goals, while for the consequencebased goals, it should be imagined as what factors are responsible for hindering the progress in the goal. The various categories of dependency factors are provided below:

- Environmental factors: Climate, weather, pollution, and natural resource availability

Table 2 Impact score for the various intensity of impacts

\begin{tabular}{|c|c|c|}
\hline Impact categories & Impact score & Description \\
\hline Catastrophic irreversible impact & 5 & $\begin{array}{l}\text { The extreme impact that wiped the progress made in the target and its effect is pronounced for } \\
\text { long-term even up to a decade }\end{array}$ \\
\hline Massive temporary impact & 4 & $\begin{array}{l}\text { Destructive impact for a short-term period that degraded the target's progress which would } \\
\text { last for a few years }\end{array}$ \\
\hline Indirect amplified impact & 3 & $\begin{array}{l}\text { Impact occurred indirectly through a cycle of effects that hinders the progress in the target for } \\
\text { a short span }\end{array}$ \\
\hline Stalled progress impact & 2 & Impact completely stalled the progress without affecting the already achieved progress \\
\hline Endurable impact & 1 & Manageable impact by finding alternative ways to make a progress to achieve the target \\
\hline Insignificant impact & 0 & Impact's effect becomes insignificant to the progress in the target \\
\hline Temporary positive drag & -1 & The impact resulted in a small boost in progress towards the target for a temporary period \\
\hline Revolutionary compliment & -2 & $\begin{array}{l}\text { A foundational positive change has been incurred that yields a promising way to progress in } \\
\text { the target }\end{array}$ \\
\hline Long-term positive reverberation & -3 & Highly amplified progress is made in the target aided by the impact \\
\hline
\end{tabular}


Table 3 Pandemic impact assessments for 17 SDGs

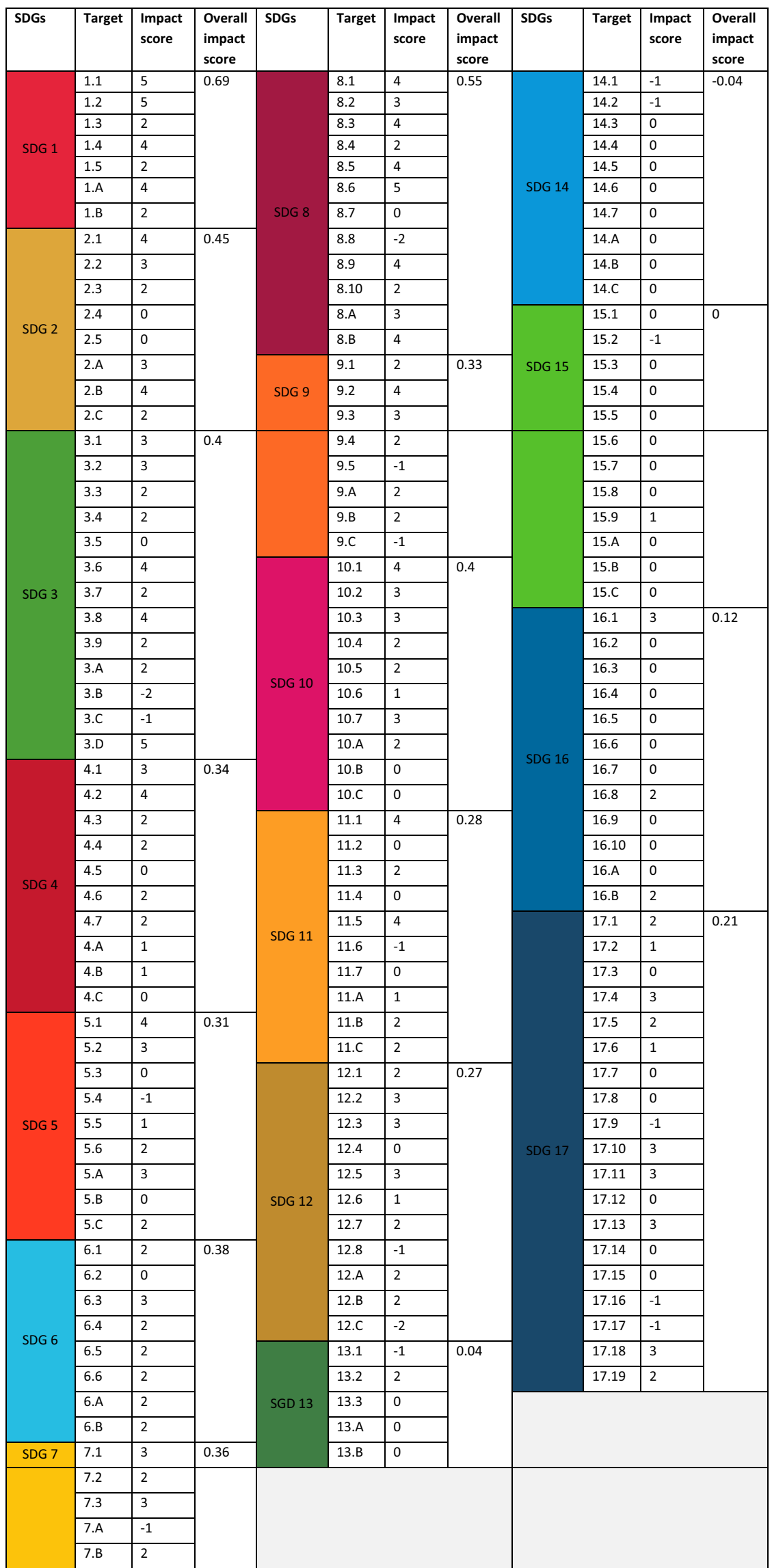


- Societal factors: Inequalities, culture, societal behavior, acceptance, and exposure

- Human development factors: Human activities, health, income, employment, agriculture, innovation, education, and partnerships

- Political factors: Governance, national and international cooperation, policies, bribery, and political vision

- Economic factors: Economy and GDP, investment capacity, exports and imports, and economic efficiency

- Technological factors: Clean energy, industries, research, and technological development

Sensitive dependency factor The sensitive dependency factor refers to a certain depending factor that can highly influence the progress in the goal than the rest of the dependency factor for a given goal. In other words, it simply marks the degree of influence of each depending factor whether high or low corresponding to a goal.

Locus of the goal Based on the sensitive dependency factor, the goals can be grouped as economy, technology, society, and environment-centered and also multi-locus-centered goals. This grouping is done to know the locus of the goal where the measures should be focused on when dealing with a particular goal.

SDG interaction As mentioned earlier, the SDGs have a complex relationship with each other, but these can be broken down into simple relations with the depending factor. If any two goals share a similar depending factor, then the possibility of one goal influencing the other is high and even interdependency might exist. With such analysis using the dependency factor and logical interpretation of targets within the goals, the interaction between the goals can be figured out. The resulting SDG interactions can be of three types: (i) a goal's progress influences other goal's progress by hastening (synergic effect) or degrading them (trade-off effect), (ii) a goal's progress depends on another goal's progress, and (iii) considered two goals progress are mutually interdependent. Key SDG interaction just involves the most significant interaction between the goals from the existing interaction.

Degree of randomness (DOR) The authors define a unique characteristic of the SDGs, namely, "degree of randomness" in the pathway of the goal. The degree of randomness simply explains the predictable nature of multiple factors on which the goal depends. This can be figured out by the general assessment of the depending factor in each goal. By assessing the randomness, one can easily know which goal can be progressed as planned provided that the execution is in line with the planning. With this parameter and SDG interaction, effective measures can be developed to hasten the progress in many goals. The quantification method for evaluating the degree of randomness is based on a simple modified ranking method (designed by authors). Here, each depending factor is analyzed for uncertainties in the progress or the possible effectiveness for an implemented measure to provide prominent progress. For instance, to achieve a target that depends on environmental factors, measures are needed from multidimensional aspects such that all people are involved in the whole process. This indicates a high level of uncertainty or randomness in the process. While implementing technological-based solutions, it is easier to process as relatively fewer contributors are required to substantiate effectiveness. This marks a low level of uncertainty or randomness. Similarly, the uncertainty involved in other factors can be reasoned. Table 4 shows the randomness score for each dependency factor. It can be observed that among the dependency factors of the SDGs, the environmental factors are the most uncertain or random factor as they cannot be controlled which is followed by societal factors and human development factors. Thus, these factors have the highest random factors and technology being more focused, less randomness prevails, and accordingly, the randomness score is the least for this factor.

From the sensitive dependency factor, it is seen that all the SDGs are not equally dependent on every factor, and thus, a weighted score needs to be considered for sensitive factors. The proposed modified weighted ranking method gives more weightage to sensitive dependency factors than the rest of the factors. This is designed with two assumptions: (i) The weightage assigned corresponding to each sensitive dependency factor and each non-sensitive dependency factor is a constant (but different constant values for sensitive and non-sensitive) for a given number of depending factors such that the summation of their weights should be less than or equal to one, and (ii) the weightage assigned to sensitive dependency factor is twice that of the rest of the dependency factors or non-sensitive dependency factors.

Table 4 Randomness score corresponding to the depending factors

\begin{tabular}{ll}
\hline Depending factors & $\begin{array}{l}\text { Random- } \\
\text { ness } \\
\text { score }\end{array}$ \\
\hline Environmental factors & 6 \\
Societal factors & 5 \\
Human development factors & 4 \\
Political factors & 3 \\
Economic factors & 2 \\
Technological factors & 1 \\
\hline
\end{tabular}


These assumptions can be formulated as shown in Eqs. (2) and (3).

$a x+b(n-x)=1-\frac{(n-x)}{2 n}$

$a=2 b$

where $x$ is the number of sensitive dependency factor that a goal possess, $n$ is the number of depending factor a goal depends on, $(n-x)$ term denotes the number of non-sensitive dependency factor, and $a$ and $b$ are the weightage corresponding to sensitive dependency factors and non-sensitive dependency factors. According to the first assumption, the weightage values of "a" and "b" are constant for a given " $n$." This is accomplished by subtracting the factor $(n-x) / 2 n$ from 1 on the right-hand side of Eq. (2). The term $(n-x) / 2 n$ will reduce to zero if all the depending factor is sensitive dependency factor, meaning that the summation of weights will equal to one. On the other hand, Eq. (3) represents the second assumption. The value of "a" and "b" is provided in Appendix 1 for every " $n$ " value. After determining the values of $a$ and $b$, the degree of randomness can be calculated using Eq. (4).

Degree of randomness $(\mathrm{DOR})=\frac{n \times\left[a \times \sum_{i=1}^{x}\left(S_{i}\right)+b \times \sum_{i=1}^{n-x}\left(D_{i}\right)\right]}{\sum \text { Randomness score of all depending factors }}$

where $S_{i}$ and $D_{i}$ are the randomness score (from Table 4) for $i^{\text {th }}$ sensitive dependency factor and $i^{\text {th }}$ non-sensitive dependency factor, respectively. Equation (4) is designed such that the DOR is distributed in the range of 0 and 1 where 1 represents a maximum DOR. Maximum DOR can be achieved only if the goal has all the six depending factors as a sensitive dependency factor. A sample calculation is presented in Appendix 1. Table 5 characterizes all SDGs in terms of the nature of goals, depending factors, sensitive dependency factor, locus of goal, SDG interaction, and degree of randomness for all goals. The results show that SDG 1, SDG 11, and SDG 12 are the goals that possess the top three highest degree of randomness, while SDG 7 and SDG 9 possesses the least degree of randomness among the seventeen SDGs.

To validate this conceptualization, the degree of randomness of each goal can be contrasted with the progress in the world for each SDG. The progress made in each SDG is represented as change since 2015 in Fig. 8. It can be observed that SDG 9 has the highest progress which is followed by SDGs 1, 3, and 11. When comparing the degree of randomness scores, SDGs 7 and 9 have the lowest scores, and it can be expected that the progress can be satisfied to quite a level. But the progress change in SDG 7 was relatively low. This is because renewable energy penetration and other initiatives towards clean energy, energy accessibility, and energy intensity were predominant only in recent years. On contrary, SDG 1 has the highest degree of randomness score yet exhibits the second-highest progress. This can be ascribed to SDG interaction as progress in SDG 9 indirectly supports the progress in SDG 1 through SDG 8. The lowest progress is observed to obtain in the goals that depend primarily on environmental factors, i.e., SDGs 12 to 15 . Altogether, the progress in a goal can be rendered as a function of the degree of randomness as well as SDG interaction.

\section{Impact nexus between pandemic and SDGs-The dynamics of SDG interaction}

This section aims to project a big picture of pandemic induced impacts across all SDGs by mapping the cumulative effect of the pandemic through the pipelines of "key SDG interaction" which is defined in Table 5. This would aid in understanding the gravity of the pandemic acting on the SDGs and also a clear understanding of the dynamics of SDG interaction can be inferred. The fundamentals of SDG interaction are depicted in Fig. 9.

Fig. 10 illustrates the dynamics of SDG interaction with pandemic impacts as an example. The various impacts are grouped at the center of the impact nexus image and are termed as impact box. The prime circle of SDGs is a conceptualized term which indicates that the goals involved in the prime circle of SDGs highly influence other goals, and their advancement will go in hand with the development in the other goals within the prime circle. The impact due to the pandemic primarily strains the health sector (SDG 3) and the goals in the prime circle (SDGs 7, 8, 9, 11). Apart from these goals, direct impact prevails in SDGs 5, 10, and 4. These are the goals that are directly impacted by the pandemic (connected directly from the impact box), and the drag (impact) may be positive (green arrows) or negative (red arrows). All the remaining impacts are caused by indirect influence (connected from one goal to another) from the affected goals as mentioned above. For example, SDG 9 is directly impacted by the implementation of lockdown. Due to which, the pollution level has significantly come down, and thus, a green medium thickness line is marked towards SDG 13 from SDG 9 meaning an indirect positive drag on SDG 13. On the other hand, the stalling of industrial operation has caused a lag in the implementation of new projects. This is depicted as a negative drag towards SDG 7, and a double arrow head is used to explain that the progress towards affordable energy is put to a temporary halt which in turn also influences the progress in SDG 9. Due to the same reason, the economy is affected, 


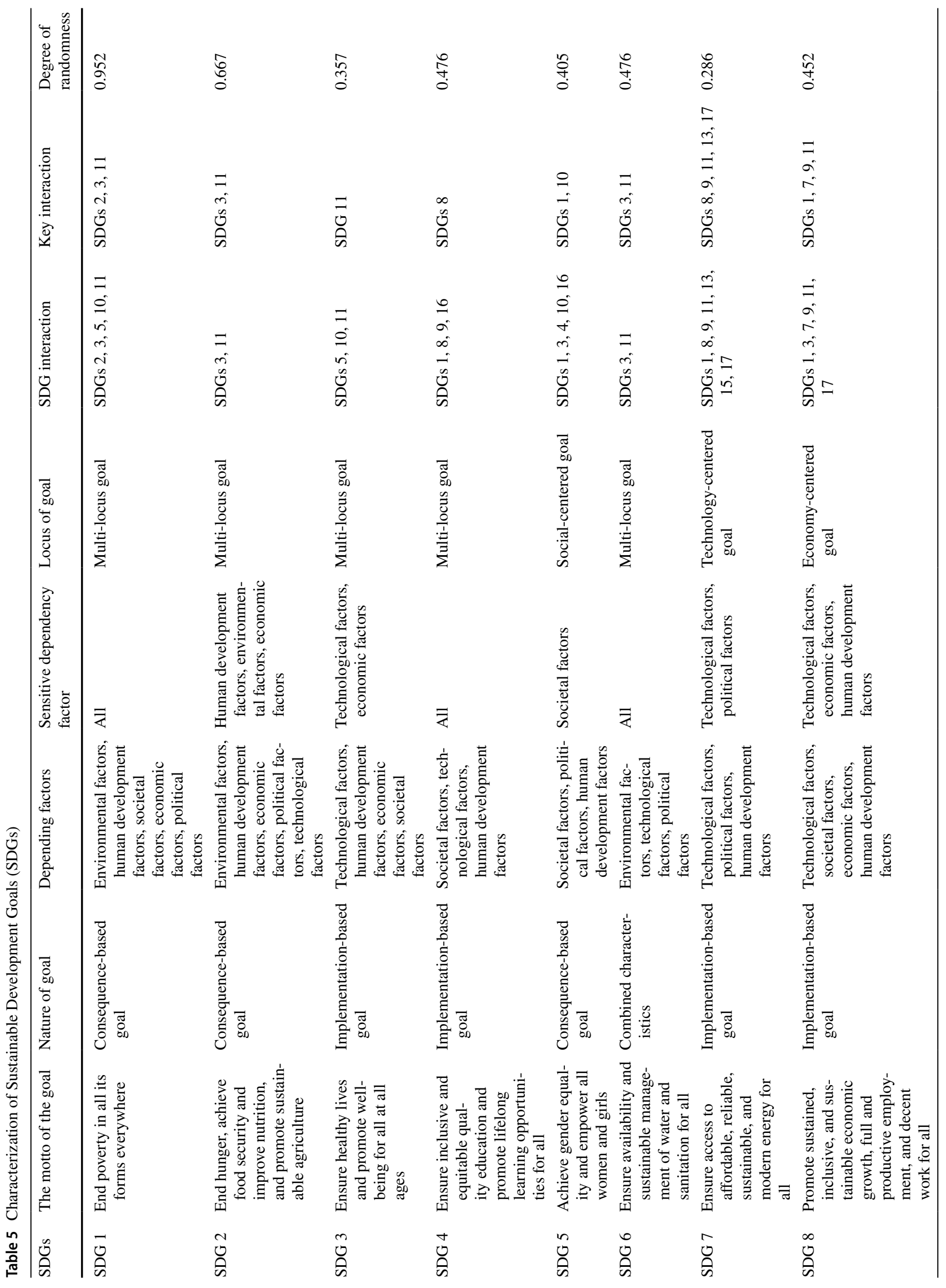




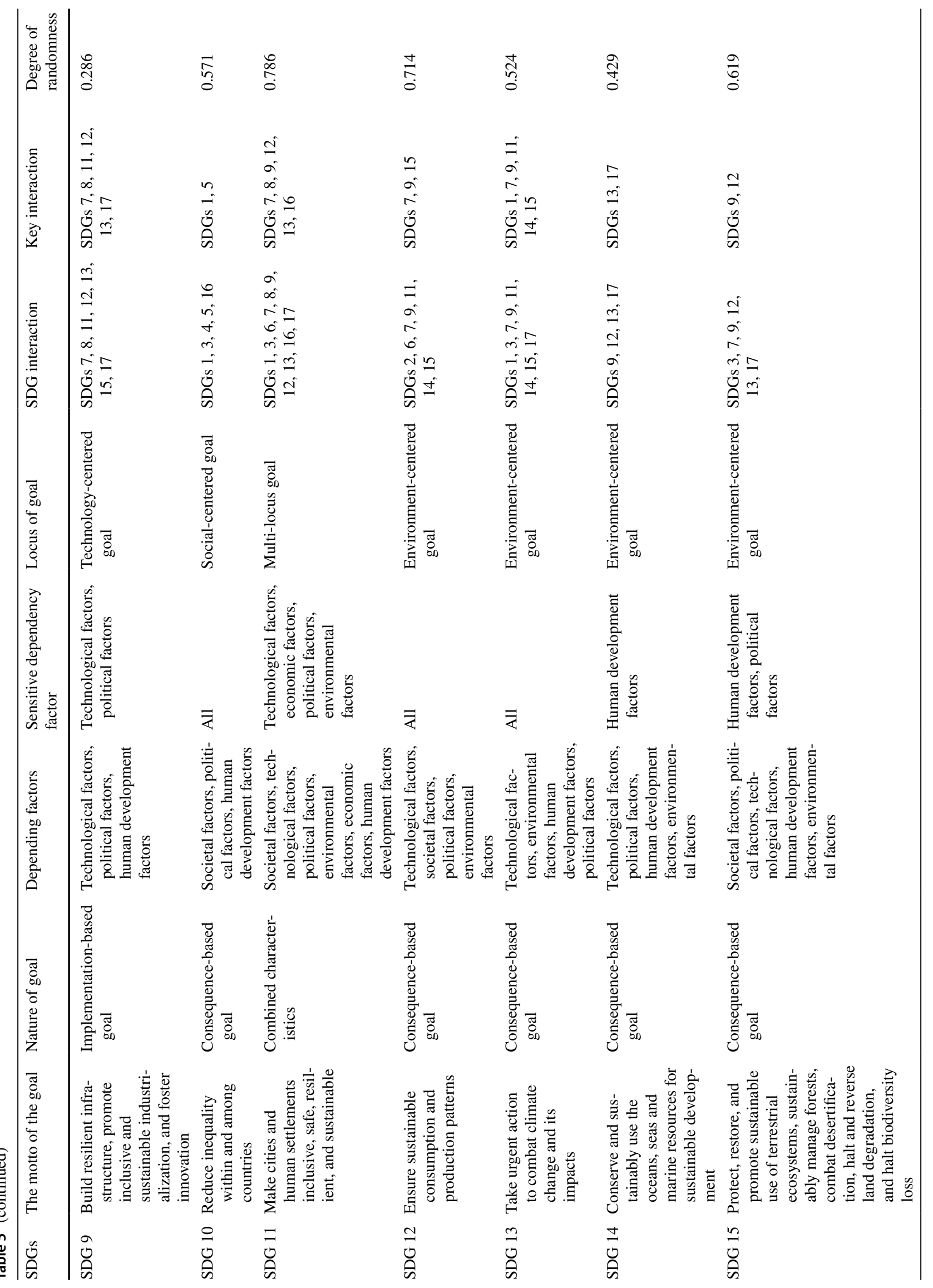




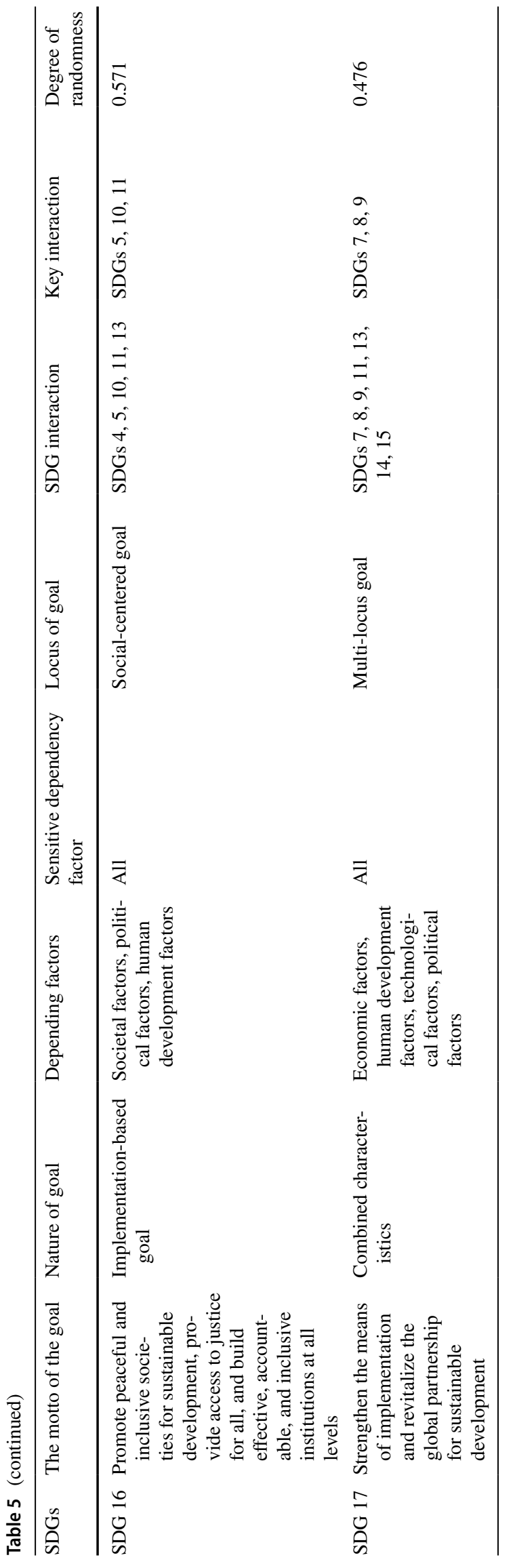

and thus, a red line is connected to SDG 8 . Since the economy influences poverty to a greater extent, a thicker red line is marked from SDG 8 to SDG 1 . Numerous red lines point towards SDG 8 and SDG 1 which aligns with the result of pandemic impact analysis on SDGs. Apart from these colored lines, the black colored lines indicate a general SDG interaction that exists between the goals. Through these interactions, minor impacts get influenced due to pandemic.

The types of SDG interaction can be interpreted through Fig. 10. For instance, let us consider SDG 8 ; here, the influencing, depending and interdependence types of SDG interaction are observed with SDGs 1,17 , and 7, respectively. Further, each type of SDG interaction can be of two different nature such as synergic and trade-off. A synergic nature of interaction means a fostering effect in the progress, while a tradeoff effect has a degrading effect in the progress of one goal when another goal involved in the SDG interaction progresses. For example, progressing in SDG 6 will have a synergic effect in SDG 3 and SDG 11, while progressing in SDG 12 might hinder the progress in SDGs 9 and 11.

When analyzing the interdependence between the goals, one goal may exert more influence on the other goal which cannot be interpreted from Fig. 10. However, the proposed new parameter, "degree of randomness", would help in analyzing the degree of influence between two interdependent goals. This can be assessed by analyzing the degree of randomness score for the involved two interdependent goals, and the low randomness goal prevails to have a higher influence on the high randomness goal. For example, consider the interdependence linkage between SDG 8 and 9. SDG 9 is a more focused goal, and hence, the degree of randomness is lower ( $\mathrm{DOR}=0.286$ ), whereas SDG 8 possesses a high degree of randomness $(\mathrm{DOR}=0.452)$ since they depend on many uncertain factors. When analyzing the extent of influence between these two goals, it is seen that influence of SDG 9 on SDG 8 is intense than the influence of SDG 8 on SDG 9 according to the randomness parameter. In other words, the development towards SDG 9 will drive the SDG 8, whereas the reverse effect is not always favorable. This inference can be evidentially proved from the pandemic impacts. For instance, stalling the industrial activities devastated the economic growth, while the impacted economy influence on industrial development is very less. As a whole, the complex SDG interaction can be interpreted using Fig. 10, but with the proposed randomness factor, one can easily understand the dynamics of SDG interaction, and the easiest approach to achieve SDGs can be drafted with such analysis which is discussed in the upcoming sections. 
Fig. 8 Progress in SDGs (world average) since 2015 in percentage points. Data source: Sustainable Development Report (2021)

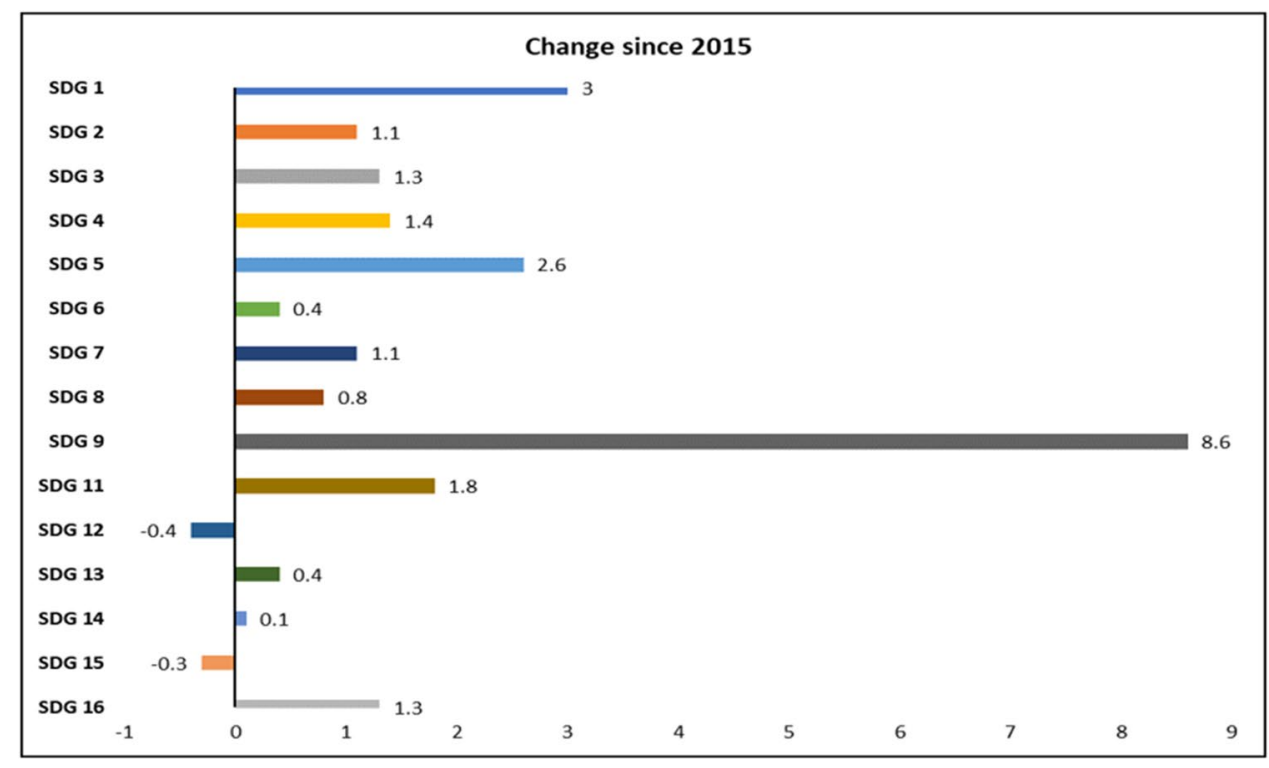

\section{Maneuvering towards SDGs in the aftermath of the pandemic}

With proper envision and effective implementation of the various means of strategies presented in this section, the pathway towards sustainability can be laid in a short time.

\section{Comprehensive strategies to accelerate the progress in the post-pandemic environment}

The authors propose various strategies to recover from pandemic impacts, but there is a pressing need to categorize

SDG interaction of Goal A with Goal B
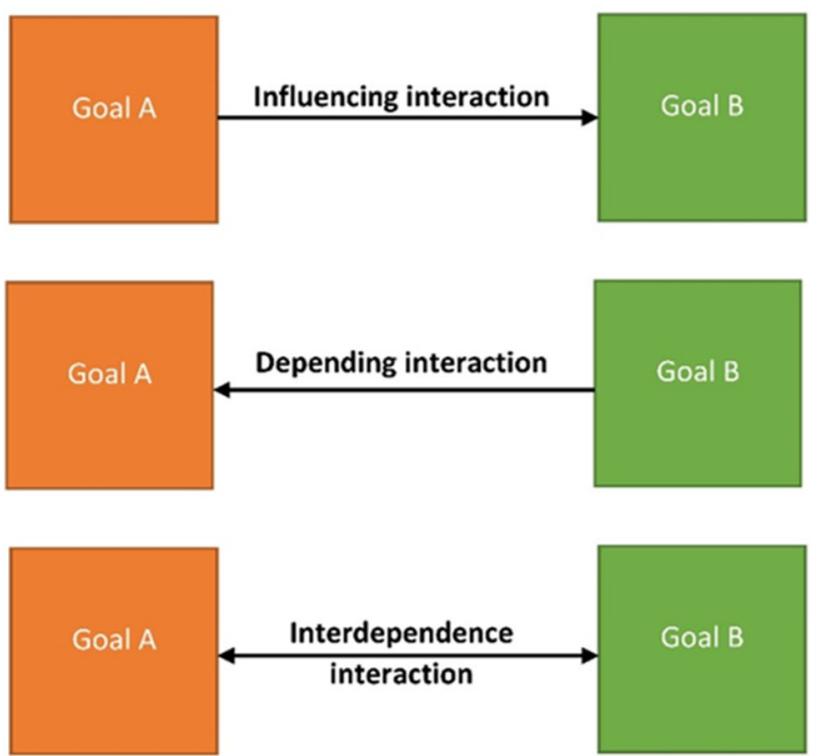

the strategies that can aid in quick revitalization as well as promote sustainability aspects. For this purpose, the authors introduce a factor, namely, prioritization factor, through with the direction of implementation primacy can be allocated. The priority factor is obtained by considering the prior need to the society since from the end of the pandemic, it varies from 0 to 1 . In this study, it is obtained through a multi-criteria analysis, following the steps provided in the analysis framework (Fig. 11). The multi-criteria analysis suggests a cumulative analysis by merging many factors, but when concerning the prioritization factor, the various evaluation criteria include the extent of the impact, synergetic interaction, and trade-off interaction with SDGs.

On investigating the impacts caused by the pandemic on SDGs, the impacts can be grouped as the categories shown in Table 6. Each category is given a score on a scale of 5 (where 5 is the most urgent and 1 is the least urgent) which is allotted based on the importance of the impact category that needs to be addressed immediately in the post-pandemic environment. For instance, the economic impact is catastrophic, and much of the society's normal functioning depends on recovering this impact. On the other hand, societal impacts such as widened inequality need a long-term recovery period. Therefore, an urgency score of 5 and 1 are allocated for economic impact and societal impact categories, respectively.

A strategy might be able to address more than one category of impacts, and to evaluate its capability to address the impacts, the impact addressal factor (IAF) is evaluated, and it is obtained by using Eq. (5).

Impact Addressal Factor (IAF)

$=\sum$ Score of Urgency for addressed impact by the strategy

Fig. 9 Fundamentals of SDG interactions 


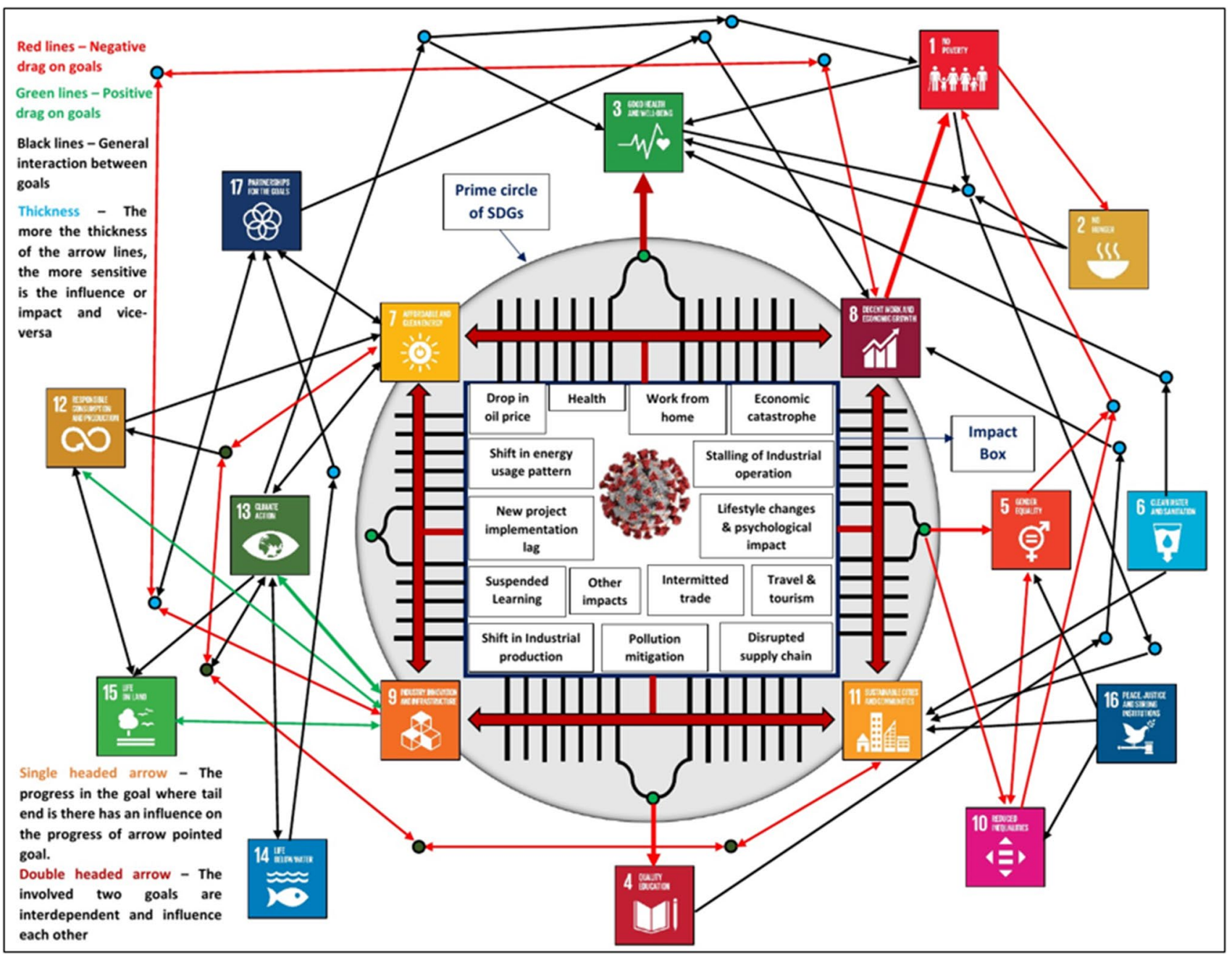

Fig. 10 Impact nexus between pandemic and SDGs

Furthermore, if a strategy helps in progressing in numerous goals at the same time, then the priority factor is designed to give more weightage for it. To determine a strategy's tendency to influence the progress in numerous goals, the SDG interaction factor is introduced which is calculated based on the SDG urgency score. This score indicates the level of urgency to focus on the progress of the considered goal, and thus, weightage is given to more affected goal. The SDG urgency score is allotted based on the overall impact score of SDGs obtained in Table 3 and is shown in Table 7. This score also varied on a scale of 0 to 5 where a score of 5 indicates a high level of urgency to direct the efforts towards the goal.

Then, the strategy for each goal is also analyzed for its ability to address other SDGs through the SDG interaction pipeline in terms of synergic or trade-off effect. The SDG interaction factor (SIF) is evaluated by using Eq. (6). In this equation, the maximum SIF can be 15; that is, even if there are numerous synergic effects that make a strategy to score SIF more than 15 , it is limited to 15 in this analysis.

SDG Interaction Factor $(S I F)=\sum($ SDG Urgency score for synergic effect SDGs $)$

$$
\text { - } \sum \text { (SDG Urgency score for trade - off effect SDGs) }
$$

Based on the obtained score for IAF and SIF, the prioritization factor for a strategy can be obtained by using Eq. (7).

$P(S)=\frac{(I A F+S I F)}{(\text { Maximum possible score })}, P(S) \in[0,1]$

A sample calculation is presented in Appendix 2. The strategies that possibly speed up the progress corresponding to each goal in the post-pandemic period are presented in Table 8 with a direction of implementation primacy defined by the prioritization factor. As a whole, the prioritization factor is obtained as a cumulative function of a strategy's tendency to address the 
Fig. 11 Multi-criteria analysis framework for determining prioritization factor pandemic impacts and also its influence in directing towards sustainability. From Table 8, the strategies that possess a prioritization factor greater than 0.5 should be given special attention in the post-pandemic environment. Focusing on the strategy that regains economy especially, creating jobs or increasing employment opportunity, and investing more in start-ups that promise sustainable technologies, reskilling of workers is the most urgent societal need that can ultimately reduce the

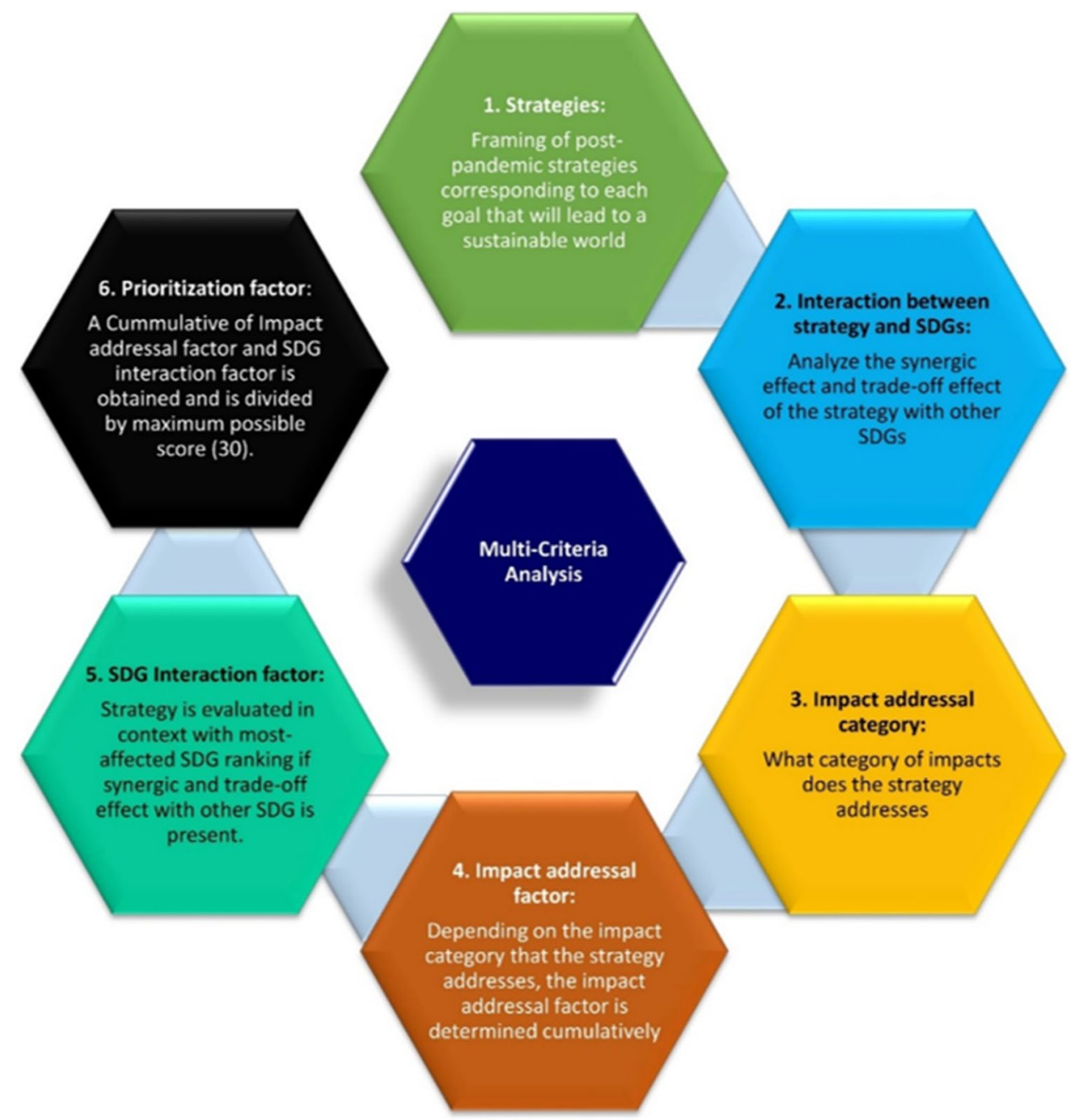

menaces imparted by the pandemic, and also, it would form a strong foundation for progressing in the direction of sustainability. Note that this analysis is carried out only to determine the strategies that ultimately help to minimize the impact of the pandemic and at the same time to direct towards sustainability. Hence, after the recovery period, every strategy should be focused on implementation.
Table 6 Impact categories and the score of urgency

\begin{tabular}{ll}
\hline Impact categories (based on pandemic impacts) & $\begin{array}{l}\text { Score of urgency (based on what } \\
\text { society needs immediately in post- } \\
\text { pandemic) }\end{array}$ \\
\hline Economic impact (E) & 5 \\
Impact on individual human (H) & 4 \\
Industrial \& energy-based impact (IE) & 3 \\
Environmental impact (EN) & 2 \\
Societal impact (S) & 1 \\
\hline
\end{tabular}


Table 7 SDG impact ranking and score of urgency

\begin{tabular}{lllc}
\hline Overall impact score range & Description & Categorized goals & $\begin{array}{l}\text { SDG } \\
\text { urgency } \\
\text { score }\end{array}$ \\
\hline 0.5 and above & Long-lasting impact & SDGs 1, 8 & 5 \\
$0.4-0.5$ & Massive temporary impact & SDGs 2, 3, 10 & 4 \\
$0.3-0.4$ & Indirect amplified impact & SDGs 6, 7, 4, 9, 5 & 3 \\
$0.2-0.3$ & Stalled progress impact & SDGs 11, 12, 17 & 2 \\
$0.0-0.2$ & Endurable impact & SDGs 16, 13, 15 & 1 \\
$-\mathrm{ve}-0.0$ & Positive impact & SDG 14 & 0 \\
\hline
\end{tabular}

\section{An outlook on implementing the strategies in the post-pandemic environment}

Apart from the various strategies corresponding to each goal, it is desirable to have a direction or roadmap for the effective implementation of strategies such that the goals can probably be achieved in a short stretch of time. Detailed mapping of SDGs in terms of strategical implementation is presented in Fig. 12. In this figure, the degree of randomness parameter (the value is shown near each SDG) and SDG interaction is used to construct this figure such that the efforts invested in the goal become more effective and efficient. The implementation-based goals mostly occupy the radially outward position. The authors propose that by progressing through the goals having a low degree of randomness from radially outside to inside in this SDG roadmap, an effective way for progressing through all the SDGs can be achieved in a short time. In Fig. 12, the goal influence (pathway) is classified based on the locus of the goals such as technology-centered, environmentcentered, economy-centered, social-centered, and multifold factor centered (meaning, a blending of above-stated factors).

If the degree of randomness is low, the implementation of strategies (assuming the execution is well established) can be expected to be effective and vice versa. This is because the degree of randomness parameter is based upon the depending factors of the goals, and in the case of advancement in high randomness goal, a strategy is required to support the

Table 8 Comprehensive strategies to accelerate the progress towards SDGs in the post-pandemic environment with prioritization factor (impact addressal category: $E$ - economic impact, $H$ - impact on indi-

vidual humans, $I E$ - industrial and energy-based impact, $E N$ - environment impact, $S$ - societal impact)

\begin{tabular}{|c|c|c|c|c|c|c|c|}
\hline SDGs & Post-COVID strategies & $\begin{array}{c}\text { Synergic effect } \\
\text { of strategy } \\
\text { with }\end{array}$ & $\begin{array}{c}\text { Trade-off } \\
\text { effect of } \\
\text { strategy with }\end{array}$ & $\begin{array}{c}\text { Impact } \\
\text { addressal } \\
\text { category }\end{array}$ & $\begin{array}{c}\text { Impact } \\
\text { addressal } \\
\text { factor } \\
\text { (Max: 15) }\end{array}$ & $\begin{array}{c}\text { SDG } \\
\text { Interaction } \\
\text { factor (Max: } \\
\text { 15) }\end{array}$ & $\begin{array}{l}\text { Prioritization } \\
\text { factor }\end{array}$ \\
\hline \multirow{4}{*}{ SDG 1} & Improvement in the income of low- and middle-income workers & SDG 2,8,11 & - & $\mathrm{H}$ & 4 & 11 & 0.50 \\
\hline & $\begin{array}{l}\text { Creating jobs, supporting pay equity, establishing work schedules, eliminating chronic } \\
\text { economic insecurity. }\end{array}$ & SDG $5,8,10,11$ & - & $\mathrm{E}, \mathrm{H}, \mathrm{S}$ & 10 & 14 & 0.80 \\
\hline & Invest in affordable, high-quality child care and early education & SDG 4 & - & $\mathrm{H}$ & 4 & 3 & 0.23 \\
\hline & $\begin{array}{l}\text { Providing awareness about existing supporting policies and increasing the implementation } \\
\text { effectiveness. }\end{array}$ & - & - & $\mathrm{H}$ & 4 & 0 & 0.13 \\
\hline \multirow{3}{*}{ SDG 2} & $\begin{array}{l}\text { Enhancing the market opportunities, minimizing the trade restrictions on agricultural } \\
\text { commodities. }\end{array}$ & SDG 8,11,17 & - & $\mathrm{E}, \mathrm{H}$ & 9 & 9 & 0.60 \\
\hline & $\begin{array}{l}\text { Resilient agricultural practices to increase productivity and progress towards sustainable } \\
\text { agriculture }\end{array}$ & SDG $8,13,15$ & $\begin{array}{l}\text { Sometimes } \\
\text { with SDG } 12\end{array}$ & $\mathrm{E}$ & 5 & 5 & 0.33 \\
\hline & $\begin{array}{l}\text { Improve producer's knowledge, expanding the financial services for agricultural needs, } \\
\text { investments or loans with low interest. }\end{array}$ & SDG 17 & - & $E$ & 5 & 2 & 0.23 \\
\hline \multirow{4}{*}{ SDG 3} & $\begin{array}{l}\text { Focus on vaccine development and antiviral drugs for COVID-19 after which distribute to } \\
\text { every individual }\end{array}$ & SDG 9,10,11 & - & $\mathrm{H}$ & 4 & 9 & 0.43 \\
\hline & $\begin{array}{l}\text { Vaccine development is also needed for already existing diseases such as AIDS, tuberculosis, } \\
\text { malaria, and other non-communicable diseases. }\end{array}$ & SDG 9,11 & - & $\mathrm{H}$ & 4 & 5 & 0.30 \\
\hline & $\begin{array}{l}\text { Access to quality healthcare services for the poor and vulnerable and for accessing } \\
\text { affordable medicines }\end{array}$ & SDG 5,10 & - & $\mathrm{H}, \mathrm{S}$ & 5 & 7 & 0.40 \\
\hline & $\begin{array}{l}\text { Improve the healthcare infrastructure and strengthen the risk management strategies for } \\
\text { the national and global health crisis. }\end{array}$ & SDG 11 & - & $\mathrm{H}$ & 4 & 2 & 0.20 \\
\hline \multirow{4}{*}{ SDG 4} & Upgrade education facilities and promote digital learning & SDG 9,11,17 & - & $\mathrm{H}$ & 4 & 7 & 0.37 \\
\hline & Increase the internet accessibility across the globe & SDG 9,11 & - & $\mathrm{H}$ & 4 & 5 & 0.30 \\
\hline & Focus on quality education than quantity education & SDG 8,11 & - & $\mathrm{H}, \mathrm{S}$ & 5 & 7 & 0.40 \\
\hline & $\begin{array}{l}\text { Equitable education for both boys and girls, expanding the scholarships for talented and } \\
\text { skilled young minds especially in developing countries. }\end{array}$ & SDG 5,10,11 & - & $\mathrm{s}$ & 1 & 9 & 0.33 \\
\hline \multirow{3}{*}{ SDG 5} & $\begin{array}{l}\text { Stringent rules and policies for eliminating all forms of violence emerged due to gender } \\
\text { inequality. }\end{array}$ & SDG 16 & - & $\mathrm{s}$ & 1 & 1 & 0.07 \\
\hline & Enhance the equity in economic, political and public life especially in decision-making. & SDG 8,11,16 & - & $\mathrm{S}$ & 1 & 8 & 0.30 \\
\hline & Impart awareness to change the societal view about women by appealing psychologically. & - & - & $\mathrm{s}$ & 1 & 0 & 0.03 \\
\hline
\end{tabular}


Table 8 (continued)

\begin{tabular}{|c|c|c|c|c|c|c|c|}
\hline \multirow{3}{*}{ SDG 6} & $\begin{array}{l}\text { Eliminate dumping wastes into water bodies, minimize water pollution, encourage treating } \\
\text { of industrial effluents and wastewater treatment. }\end{array}$ & $\begin{array}{l}\text { SDG } 9 \\
\text { (Innovation), } \\
13,14\end{array}$ & $\begin{array}{l}\text { SDG } 9 \\
\text { (Industrial } \\
\text { development) }\end{array}$ & EN & 2 & 1 & 0.10 \\
\hline & $\begin{array}{l}\text { Frame solutions with a long-term vision to reduce water scarcity with sustainable } \\
\text { consumption and supply of freshwaters. }\end{array}$ & SDG 3 & - & $\mathrm{H}$ & 4 & 4 & 0.27 \\
\hline & $\begin{array}{l}\text { Promote integrated water resource management, desalination plants and protect natural } \\
\text { eco-system. }\end{array}$ & SDG $14,15,17$ & $\begin{array}{l}\text { SDG } 15 \text { - for } \\
\text { integrated } \\
\text { water } \\
\text { resource }\end{array}$ & $\mathrm{H}, \mathrm{EN}$ & 6 & 2 & 0.27 \\
\hline \multirow{4}{*}{ SDG 7} & Digitalization of the energy sector, improve reliability, flexibility and efficiency. & SDG 9,11,17 & - & IE & 3 & 7 & 0.33 \\
\hline & $\begin{array}{l}\text { Focus on renewable energy penetration for both power and heat as well as decrease the } \\
\text { share of non-renewables }\end{array}$ & SDG 8,9,11,13 & SDG 12,15 & $\mathrm{IE}, \mathrm{E}, \mathrm{EN}$ & 10 & 8 & 0.60 \\
\hline & $\begin{array}{l}\text { Engage research activities towards clean energy and technology and also, optimize the } \\
\text { existing system in terms of affordability. }\end{array}$ & SDG 9,13 & - & $\mathrm{IE}, \mathrm{EN}$ & 5 & 4 & 0.30 \\
\hline & Investing more in start-ups dealing with renewables and sustainable modernization. & $\begin{array}{l}\text { SDG } \\
8,9,11,13,15,17\end{array}$ & - & $\mathrm{E}, \mathrm{IE}, \mathrm{EN}$ & 10 & 14 & 0.80 \\
\hline \multirow{5}{*}{ SDG 8} & Shifting the concentration towards the green economy & SDG 13,14,15 & - & E,EN & 7 & 2 & 0.30 \\
\hline & Expanding the agricultural markets & SDG 2 & - & $E, H$ & 9 & 4 & 0.43 \\
\hline & Widening the employment opportunities and emphasis on work from home opportunities & SDG 1, 11 & - & $E, H$ & 9 & 7 & 0.53 \\
\hline & Reskilling of employers & SDG 7,9,11,17 & & $\mathrm{E}, \mathrm{H}, \mathrm{IE}$ & 12 & 10 & 0.73 \\
\hline & Improving the trade relationships and partnerships, and promoting foreign investments & SDG 9,17 & - & $\mathrm{E}, \mathrm{IE}$ & 8 & 5 & 0.43 \\
\hline \multirow{4}{*}{ SDG 9} & $\begin{array}{l}\text { Sustainable manufacturing, effective supply chain management, value chain management } \\
\text { and automation is the key to SDG } 9\end{array}$ & SDG 8 & - & $\mathrm{IE}, \mathrm{E}$ & 8 & 5 & 0.43 \\
\hline & Development of industries by reducing energy intensity and carbon intensity & SDG 8,11 & - & $\mathrm{IE}, \mathrm{E}, \mathrm{H}$ & 12 & 7 & 0.63 \\
\hline & Diversification of global manufacturing sectors and interdependencies among industries & SDG 17 & - & $\mathrm{IE}, \mathrm{E}$ & 8 & 2 & 0.33 \\
\hline & Investments in research concerning innovations, optimization and technological capabilities & SDG 7,11 & - & IE & 3 & 5 & 0.27 \\
\hline \multirow{3}{*}{ SDG 10} & Ensure equal opportunity in jobs and reduce inequalities of outcome & SDG 4,5 & - & $\mathrm{s}$ & 1 & 6 & 0.23 \\
\hline & Provide awareness to drive equality in the people mindset or behavior & - & - & $\mathrm{S}$ & 1 & 0 & 0.03 \\
\hline & Enhance the equity in economic, political and public life especially in decision-making. & SDG 5,8,11,16 & - & $\mathrm{s}$ & 1 & 11 & 0.40 \\
\hline SDG 11 & $\begin{array}{l}\text { Sustainable agriculture, sustainable energy production and management, sustainable } \\
\text { manufacturing are the foundation for sustainable cities. } \\
\text { Refer strategies in SDG } 2,7,8,9 \text {. }\end{array}$ & - & - & - & - & - & - \\
\hline SDG 12 & $\begin{array}{l}\text { Promoting optimization techniques in industries for reducing material consumption and } \\
\text { waste generation. }\end{array}$ & SDG 9,11,14,15 & - & EN,IE & 5 & 6 & 0.37 \\
\hline
\end{tabular}

multifold depending factors of the goal which is less likely. Hence, if a strategy addresses only a few depending factors, it is possible that the effectiveness of the implemented strategy can be pulled down through the other depending factors that are not addressed. Further, the goals possessing a low degree of randomness and that are extensively interrelated to other goals should be prioritized. From the analytic representation of SDG interaction illustrated in Fig. 10, the highly interrelated SDGs belong to the prime circle, and among which, SDGs 7 and 9 possess a low degree of randomness. Thus, in a post-pandemic environment, after the economy is regained, focusing on SDGs 7 and 9 followed by the environment-centered goals would prevail as a better way for effectuating the strategies.

Also, super prioritizing the strategies that have the highest prioritization score in Table 8 corresponding to SDG 7 and 9 is necessary. On focusing the SDGs 7 and 9 from the technological aspect with the aid of partnerships, these goals can have a positive impact on the rest of the goals, and when the approaches are blended with the environmental concerns, the foundation for the sustainable world is laid. For instance, the major environmental concerns are the need for minimal degradation of resources, optimized consumption, and the addressal of key causes for climate change. Without integrating these concerns with the progress, the green pathway will be completely obstructed and severe after effects would be seen in the black pathways as well since the environmental concerns also influence them. Directing the developments relevant to SDG 9 in an economically beneficial and environmentally favorable approach is crucial (IRENA 2020b; Kynclova et al. 2020). On the other hand, SDG 7 is on the right path progressing towards renewables, but the progress further needs to be hastened, and affordability has to be imparted in the energy sector.

As the progress in SDGs 7 and 9 happens in the postpandemic world, large employment opportunity prevails, but it requires reskilling of workers to grasp the opportunities (IRENA 2020b). With sufficient progress in SDGs 7 and 9, SDG 8 will rebound from the pandemic impact, and if the restructuring of the labor market, as well as reskilling, is carried out, then SDG 1 would again witness a revamped progress. This will minimize the pandemic impact to a greater extent. The progress in SDGs 6, 5, 10, and 16 is less interactive with other SDGs, and they need lots of effort and focus to gain significant progress. Further, implementing the strategies based on the prioritization factor under each goal will accelerate the progress towards sustainability. Therefore, the authors claim that initiating the presented strategies based on the prioritization factor and the degree of randomness would ultimately enhance the effectiveness in the implementation which will result in a shorter period of achievement of all SDGs from the management perspective. Besides, monitoring 
Table 8 (continued)

\begin{tabular}{|c|c|c|c|c|c|c|c|}
\hline & $\begin{array}{l}\text { Prioritize reduce, recycle, reuse, refurbish, remanufacture, repurposing and reduction at } \\
\text { design strategies. }\end{array}$ & SDG 11,15 & - & EN,IE & 5 & 3 & 0.27 \\
\hline & Effective use of fossil fuels and gradually decreasing their use especially in the energy sector. & SDG 7 & - & EN,IE & 5 & 3 & 0.27 \\
\hline & $\begin{array}{l}\text { Measures for minimizing food losses in the supply chain and encouraging the distribution of } \\
\text { excess foods to the poor and needy. }\end{array}$ & SDG 2 & - & $\mathrm{H}, \mathrm{S}$ & 5 & 4 & 0.30 \\
\hline \multirow{4}{*}{ SDG 13} & Framing new policies and effectively implementing the existing policies related to SDG-13 & SDG 7,9 & - & EN & 2 & 6 & 0.27 \\
\hline & $\begin{array}{l}\text { Upcoming technologies and developments must be strictly given importance by considering } \\
\text { the environmental effects. }\end{array}$ & SDG 14,15 & - & EN & 2 & 1 & 0.10 \\
\hline & $\begin{array}{l}\text { Focusing on harvesting renewable sources of energy and emphasis on decarbonization } \\
\text { strategies }\end{array}$ & SDG 7,9 & $\begin{array}{l}\text { Sometimes } \\
\text { SDG } 12,15\end{array}$ & EN, IE & 5 & 3 & 0.27 \\
\hline & $\begin{array}{l}\text { Integrate measures to mitigate environmental pollution and also impart those in the human } \\
\text { behavioral patterns by constant awareness through various means. }\end{array}$ & $\begin{array}{l}\text { SDG } \\
3,6,9,14,15\end{array}$ & - & EN & 2 & 11 & 0.43 \\
\hline \multirow{4}{*}{ SDG 14} & Effective management to avoid empty shipping containers traversing through the sea. & SDG 13 & - & EN & 2 & 1 & 0.10 \\
\hline & $\begin{array}{l}\text { Eliminate the dumping of plastic waste into the oceans and more importantly, the COVID-19 } \\
\text { medical wastes such as masks, PPE. }\end{array}$ & - & - & EN & 2 & 0 & 0.07 \\
\hline & $\begin{array}{l}\text { Restricting the destructive fishing practices, protecting coral reefs and conserving the } \\
\text { coastal and marine areas to the maximum extent. }\end{array}$ & SDG 13 & - & EN & 2 & 1 & 0.10 \\
\hline & Technological focus on ocean acidification and address the root cause for the same. & - & - & EN & 2 & 0 & 0.07 \\
\hline \multirow{3}{*}{ SDG 15} & $\begin{array}{l}\text { Restore degraded land and fertility, promote afforestation and sustainable agricultural } \\
\text { practices. }\end{array}$ & SDG 2,13 & - & EN & 2 & 5 & 0.23 \\
\hline & $\begin{array}{l}\text { Promote native species, ensure that cities infrastructure and design support sufficient } \\
\text { greeneries. Identify key species in promoting biodiversity in different geographical regions } \\
\text { and conserve the same. }\end{array}$ & - & - & EN & 2 & 0 & 0.07 \\
\hline & Refer strategies in SDG 12, 13. & - & - & - & - & - & - \\
\hline \multirow{3}{*}{ SDG 16} & Laws should be verified for their existing purpose to promote justice & SDG 11 & - & $\mathrm{S}, \mathrm{H}$ & 5 & 2 & 0.23 \\
\hline & Eliminate corruption and bribery in all aspects. & SDG 11 & - & $\mathrm{S}$ & 1 & 2 & 0.10 \\
\hline & $\begin{array}{l}\text { Transparency to the public, justice acts, promoting the right to express, information and } \\
\text { equality will favor a peaceful society. }\end{array}$ & SDG 11 & - & S & 1 & 2 & 0.10 \\
\hline SDG 17 & Promote partnerships in all aspects and direct the investments towards sustainability. & SDG 7, 8, 9, 11 & - & $\mathrm{IE}, \mathrm{E}$ & 8 & 13 & 0.70 \\
\hline
\end{tabular}

and evaluating the progress are pivotal. A study by Allen et al. (2019) adopted a multi-criteria analysis on the various SDGs to assess and prioritize the targets based on urgency, systematic impact, and policy gap in 22 countries of the Arab region. The study intends to analyze the strengths and weaknesses of baseline assessment and benchmarking of indicators, systems and network analysis of target interlinkages, and mapping of policy alignment and gaps. Also, it highlights how they can be applied together. Such studies are encouraged as they give an idea of where we have currently headed and the loopholes for the improvement can also be identified through such analysis. Hence, mapping provides an effective direction, while analysis helps us to monitor whether the propagation is in alignment with the direction.

\section{A conceptual framework to define SDG-aligned business practices}

Apart from the strategies to achieve the goals, aligning the business practices with the SDGs which works in a decentralized methodology would also ultimately lead to the path of sustainability. The decentralized approach demonstrates that the efforts are accumulated from the bottom-up approach, meaning that business firms are coming forward to align their business practices with SDGs without any centralized regulations forcing the business firms. Although a centralized approach can offer benefits in terms of common goals and progress, a decentralized approach can unleash the sustainability potential of individual business firms since the goals and targets are constructed by the companies depending on their capability. This can provide numerous advantages such as flexibility, effective progress, firm-specific plans, increase in innovative management, and greater concerns to sustainability. Due to the aforementioned merits of decentralized approach, it is also beneficial than a distributed approach where the planning and control process can be centralized to a certain extent. Since the proposed framework encourages a decentralized approach, the organization can plan according to their value chains, and their decisions can be free from the influence of other firms. While in the case of distributed approach, the similar targets can be applicable for a group of firms sharing common value chain, but integrating SDGs will face unwanted constraints due to difference in the scale of market share.

At present, it is obvious that current business practices harm the environment and is not on par with sustainability. The entire world is under an acute economic and social crisis with no way of knowing when the normality will return (UN Environment Programme 2020). In the postCOVID-19 scenario, the organizations will face difficulties with capital gains and growth. Due to which, the business practices in the post-COVID-19 world might experience a significant change. This can be considered an opportunity to direct the changes towards sustainability. Thus, the proposed conceptual framework to align the business practices with the SDGs would promote sustainability 


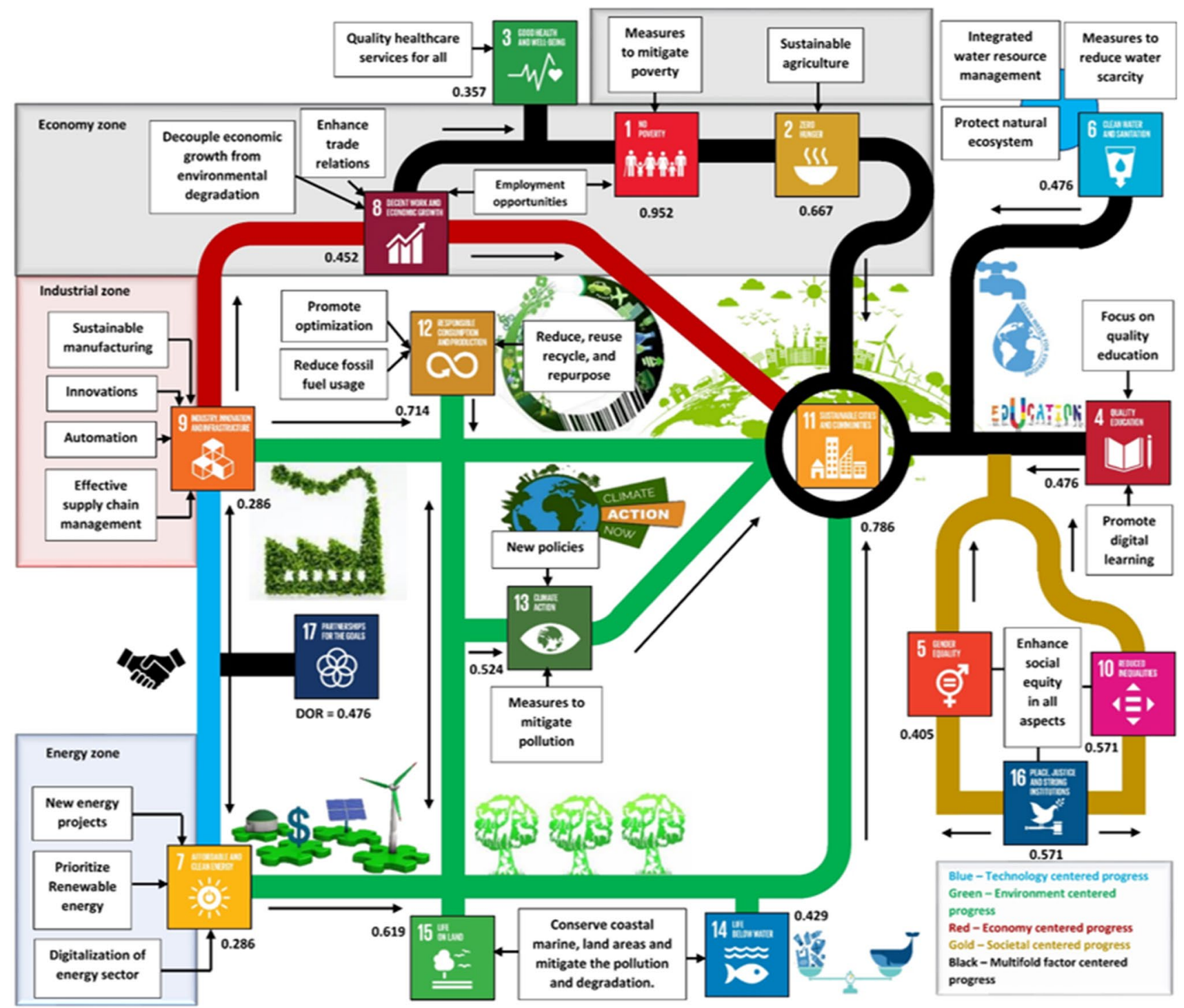

Fig. 12 Strategic implementation of SDGs based on SDG interaction and degree of randomness

and also enhance the business practices in the post-pandemic world. But such practices need a strategic action that can only be achieved with proper planning that is in line with the SDGs engagement. In general, any business practice revolves around four key themes, which include purpose, capital, growth, and risk, as shown in Fig. 13. If the business practice should be aligned with SDGs, the organizations should integrate the goals into their strategic management process. For such integration, the following framework that is built upon the SDG Compass is proposed for post-COVID-19 world business practices (SDG Compass 2020). The SDG Compass is mainly based on the five steps as shown in Fig. 14.

The five steps are briefly described below (SDG Compass 2020):
Step-1: In the first step, every organization that is planning to have SDG-aligned business practices should have complete knowledge of all the 17 SDGs and their target indicators. Apart from having knowledge of the SDGs, the organization should understand its business case and development perspectives to possibly align with the SDGs by respecting the business responsibilities.

Step-2: In the second step, priorities are defined. But before defining the priorities, the organization should have a complete view of the value chain (e.g., from the raw material to the end of life) based on the product or service offered. In this step, the mapping of SDGs with the organization value chain is to be carried out. It should be noted that not all 17 SDGs can be mapped. Once the 


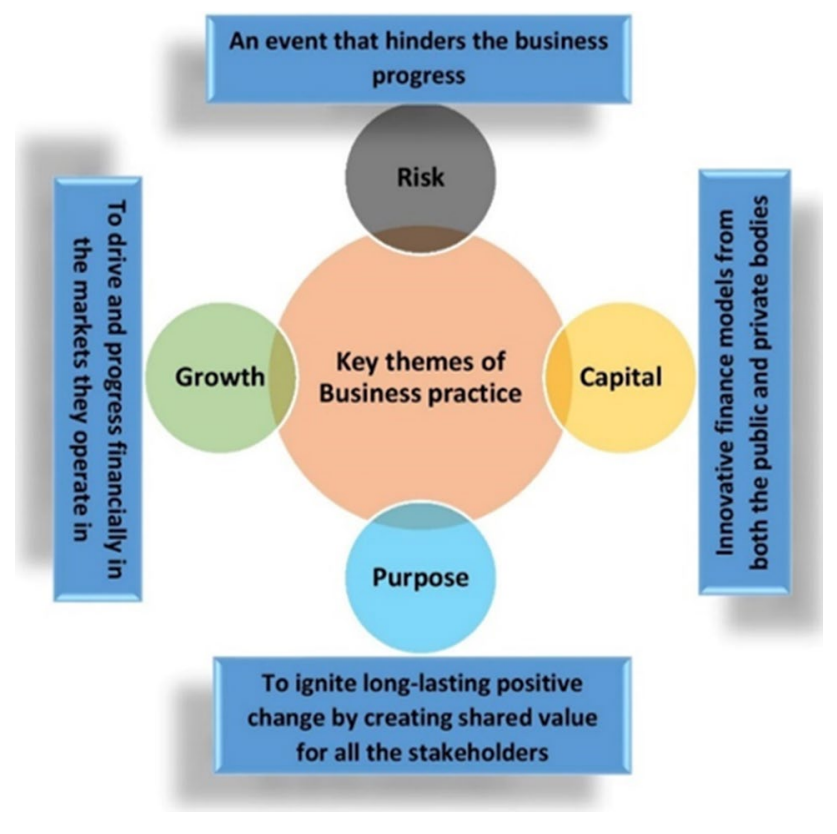

Fig. 13 The four key themes of business practice

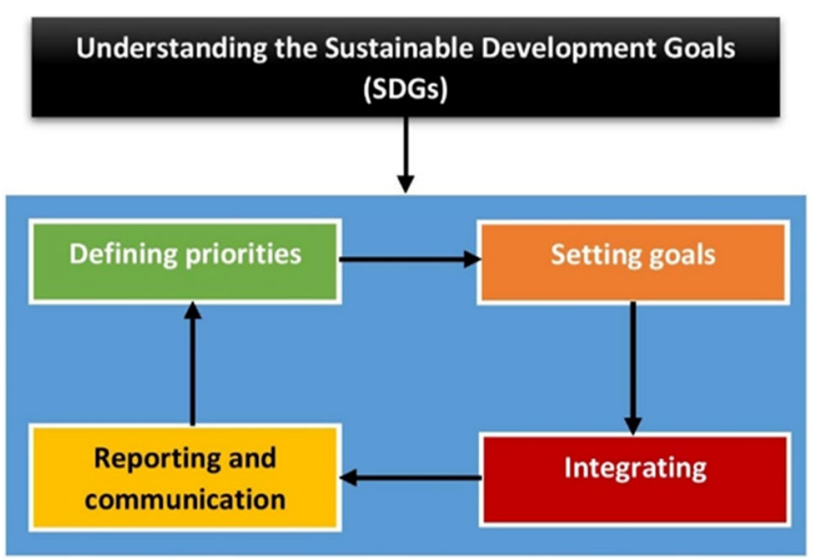

Fig. 14 A five-step SDGs compass framework for SDGs aligned business model

mapping is done, specific indicators and data should be selected. These indicators and the data are mainly based on the value chain.

Step-3: In the third step, goal setting is ensured. In any business practice, goal setting is more crucial and enables the organization to have certain baseline goals and ambitions upon which the organization would demonstrate its commitment to sustainable development.

Step-4: The fourth step primarily focuses on integrating sustainability into the "core business and governance and embedding sustainable development targets" across all functions within the value chain of the organization. In this step, organizations need to have effective engagement with partnering organizations across the product or service value chain.

Step-5: In this step, information related to the SDGs performance based on set priorities considering the indicators selected throughput the value chain is reported. This reported information is further communicated within the stakeholder's group.

A careful assessment of the value chain involved in the organization and integrating various possible SDGs with the process of organization is vital and a challenging task. A detailed framework to aid in integrating the goals with the business case is illustrated in Fig. 15. Apart from the voluntary alignment of SDGs into business practices by the

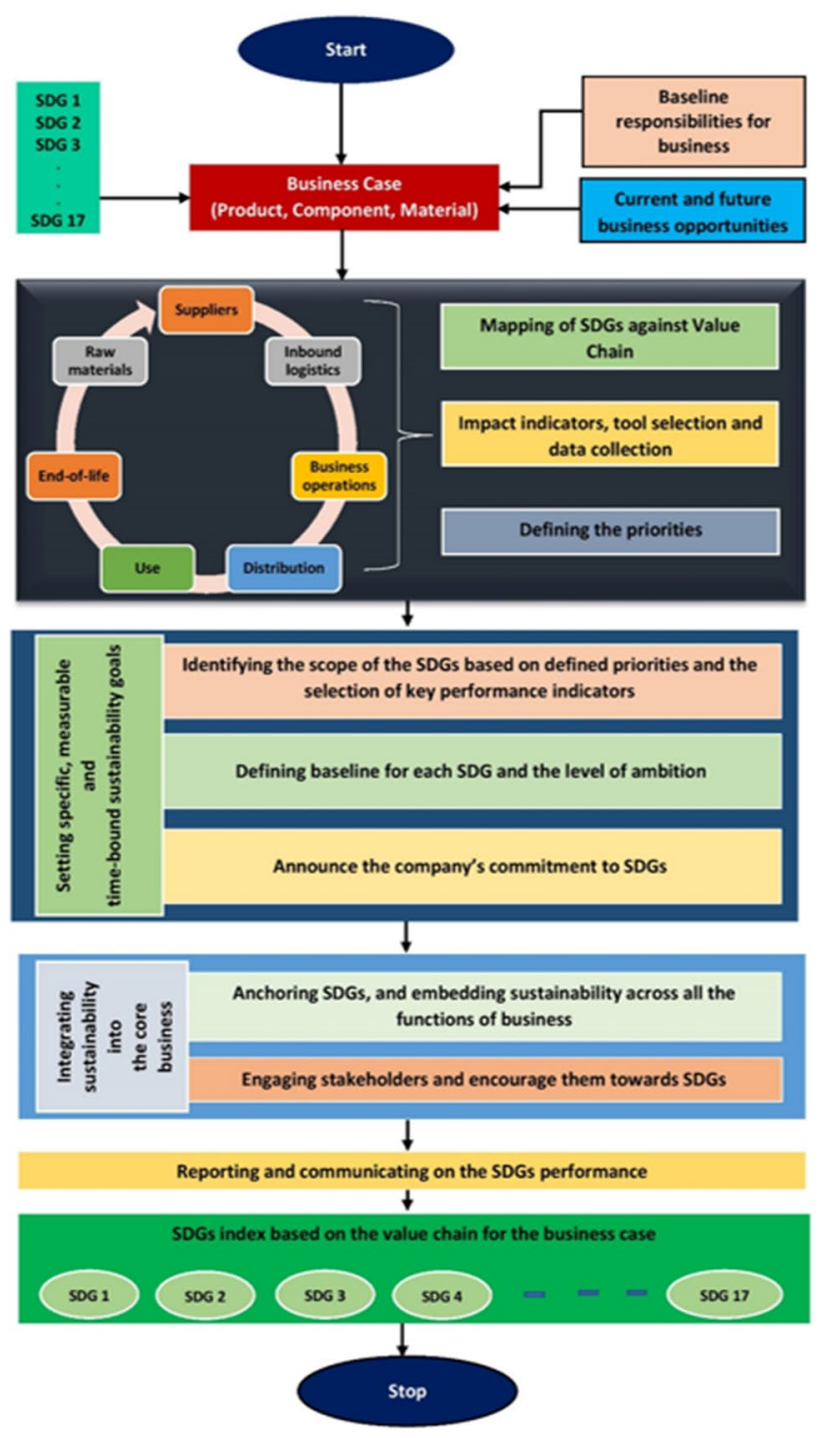

Fig. 15 Conceptual framework to align business practices with SDGs 
organizations, it should be more welcomed by the stakeholders, and capitalism for environmentalism should be prioritized for lending investments to the respective businesses. Through these approaches, the penetration of SDGs into various sectors can be enhanced. The tax system for the business can be also extended to expect contribution from the companies to focus on establishing a sustainable society.

\section{Discussions and conclusions}

The progress towards SDGs is significantly impacted due to the COVID-19 pandemic. A detailed investigation on the impact of the pandemic on each SDG is drawn. Quantified impact analysis is performed by assessing the impact that occurred in each target of the goals. The results indicate that SDG 1 is the most impacted goal followed by SDG 8 with a score of 0.69 and 0.55 , respectively. In the aftermath of the pandemic, the human response in regaining the economy will be the ultimatum for the extent of poverty rise. Only SDG 14 has managed to possess a little positive impact with an overall impact score of -0.04 .

The brief concepts of SDGs are formulated from their elemental nature, and the factors such as nature of the goal, depending factors, sensitive dependency factor, and locus of goal are defined for each goal. The nature of goal, depending factor, and the locus of goal are considered to analyze the SDG interactions. Meanwhile, the depending factor and sensitive dependency factor are used to quantify the proposed novel degree of randomness factor with the designed modified weighted ranking method. It is seen that SDGs 1 and 11 possess a high degree of randomness with scores of 0.952 and 0.786 , respectively. On the other hand, the goals that have the least degree of randomness include SDG 7 and SDG 9, sharing an equal score of 0.286 .

The impact interaction between the SDGs is insightful in understanding how the SDGs depend or influence each other, meaning that it paves a way for understanding the dynamics of SDG interaction. It can be inferred from the analysis that SDGs 7, 8, 9, and 11 have the most interaction with other goals (the prime goals) and are crucial in manipulating the advancement in every other goal. The SDG interaction through the impact nexus figure is explained which include influencing, depending, and interdependent types of SDG interactions. Further, the synergic and trade-off nature of the interaction is established. Interdependency is a special case of SDG interaction and is further analyzed to determine which SDG has more influence among two interdependent goals using the degree of randomness. It shows that in the interdependent goals, the goal which has a low degree of randomness influences the other goal to a higher extent. All these analyses and observations provide with a big picture of SDG interaction and deep insight regarding the nature of goals.

To carry out the progress in each goal in the postpandemic period, the strategies are framed and presented. The prioritization factor is designed and is formulated based on multi-criteria analysis. This factor indicates the strategy's ability to address the impact caused by the pandemic and simultaneously direct the progress right in the path of sustainability. According to the results of the prioritization factor, the strategies such as expanding employment opportunities with equality, investing more in start-ups dealing with renewables and modern sustainable technologies, reskilling of labors, and promoting partnerships and investment towards sustainability are the top strategies that should be prioritized in the post-pandemic period.

By blending all the analyses made in the study (such as SDG interaction, degree of randomness of the goal, framing the strategies with prioritization factor), the mapping of SDGs for effectively implementing the strategies to attain a sustainable world is presented. The results emphasized that the progress in SDGs 7 and 9 should be focused in the post-pandemic environment through which the advancement towards the other goals can be expedited if the approach is environmentally favorable and also supports the economic development. Further, when implementing the strategies based on the prioritization factor for each goal, sustainability is favored in all aspects and can be achieved in a short period of time.

Further, the conceptual framework for aligning the business practices with respect to SDGs is elaborated. The biggest challenge in aligning them is that it requires greater understanding to yield proper planning as well as to find an optimal way to balance the synergic and trade-off effect that would possibly occur in a firm. As a whole, this study will be supportive to policy-makers, governments, researchers, industrialists, business analysts, and professionals for directing their efforts towards sustainability, incorporating the proposed concepts, and making solid decisions and the like, related to SDGs. A novel insight related to SDGs is well established to continue the developments in human society. To conclude, humans should perceive the current situation as an opportunity to tune themselves to impart actions and developments such that it ultimately favors the sustainable world. 


\section{Appendix 1}

\section{Degree of randomness calculation}

Let us consider SDG 2 as an example. The depending factors are environmental factors, human development factors, economic factors, political factors, and technological factors. The sensitive dependency factors are human development factors, environmental factors, and economic factors. Therefore, in this case, $n=5$ and $x=3$. Substituting $n$ and $x$ values in Eqs. (2) and (3) and solving them would yield the values of $a$ and $b$.

$a=0.2$

$b=0.1$

Similarly, the calculated constant values of a and b corresponding to different values of $\mathrm{n}$ is presented in Table 9. The degree of randomness can be calculated from Eq. (4) which is given as follows:

Degree of randomness $(D O R)=\frac{n \times\left[a \times \sum_{i=1}^{x}\left(S_{i}\right)+b \times \sum_{i=1}^{n-x}\left(D_{i}\right)\right]}{\sum \text { Randomness score of all depending factors }}$

From Table 4, the randomness score for the factors can be allocated.

The randomness scores for sensitive dependency factor (Si) are as follows:

Human development factors, $\mathrm{S} 1=4$

Environmental factors, $\mathrm{S} 2=6$

Economic factors, $\mathrm{S} 3=2$

The randomness scores for the non-sensitive dependency factor (Di) are as follows:

Political factor, D1 = 3

Technological factors, D2 = 1

Note that the denominator indicates the summation of all the randomness scores of all depending factors, and it does not mean that it is limited only to the factors that the goal under consideration depends on (Table 9).

Denominator value $=6+5+4+3+2+1=21$

$D O R=\frac{5 \times[0.2 \times(4+6+2)+0.1 \times(3+1)]}{21}=0.667$

Table 9 The values of $a$ and $b$ for every $n$ value

\section{Appendix 2}

\section{Prioritization factor calculation}

Let us consider a strategy in Table 8, "Investing more on start-ups dealing with renewables and those drives the world towards sustainable modernization" under SDG 7.

When analyzing what type of impacts this strategy would address, it can be seen that it addresses the impact categories such as the economy (E), environment (EN), and industry and energy (IE). The impact addressal factor (IAF) can be evaluated using Eq. (6), and the impact scores corresponding to each impact category can be extracted from Table 6.

$$
I A F=5+2+3=10
$$

Though this strategy directly helps in progressing towards SDG 7, it also helps in other SDGs such as SDGs 8, 9, 11, 13,15 , and 17. This indicates a synergic effect in these goals, and the trade-off effect is not reflected in any of the goals.

Depending on the SDG urgency score as represented in Table 7, the cumulative scores for synergic effect can be obtained as follows:

Synergic effect score $=$ scores of $($ SDG $8+$ SDG $9+$ SDG $11+$ SDG $13+$ SDG $15+$ SDG 17).

$=5+3+2+1+1+2$

$=14$

Trade-off effect score $=0$

The SDG interaction factor (SIF) score can be evaluated as follows:

$\mathrm{SIF}=$ synergic effect score-trade-off effect score $=14$.

The maximum possible score is 30 .

Prioritization factor $=(\mathrm{IAF}+\mathrm{SIF}) / 30=(10+14) / 30=0.8$

Author contribution Rajvikram Madurai Elavarasan: Conceptualization, formal analysis, investigation, methodology, supervision, visualization, validation, writing — original draft, and writing—review and editing

Rishi Pugazhendhi: Conceptualization, formal analysis, data curation, investigation, methodology, visualization, and writing—original draft

GM Shafiullah: Formal analysis and review and editing

Nallapaneni Manoj Kumar: Writing and visualization

M. T. Arif: Formal analysis and review and editing

Taskin Jamal: Formal analysis and review and editing

Shauhrat S. Chopra: Review and editing

Joanna Dyduch: Review and editing

Data availability Not applicable

\section{Declarations}

Ethics approval and consent to participate Not applicable

Consent for publication Not applicable

Competing interests The authors declare no competing interests. 


\section{References}

Aguilar GR, Sumner A (2020) Who are the world's poor? A new profile of global multidimensional poverty. World Dev 126:104716. https://doi.org/10.1016/j.worlddev.2019.104716

Allen C, Metternicht G, Wiedmann T (2019) Prioritising SDG targets: assessing baselines, gaps and interlinkages. Sustain Sci 14:421. https://doi.org/10.1007/s11625-018-0596-8

Blesh J, Hoey L, Jones AD, Friedmann H, Perfecto I (2019) Development pathways toward "zero hunger." World Dev 118:1-14. https://doi.org/10.1016/j.worlddev.2019.02.004

Bouman T, Verschoor M, Albers CJ, Böhm G, Fisher SD, Poortinga W et al (2020) When worry about climate change leads to climate action: how values, worry and personal responsibility relate to various climate actions. Glob Environ Chang 62:102061. https:// doi.org/10.1016/j.gloenvcha.2020.102061

Bruns B, Macdonald IH, Schneider BR (2019) The politics of quality reforms and the challenges for SDGs in education. World Dev 118:27-38. https://doi.org/10.1016/j.worlddev.2019.02.008

Campagnolo L, Davide M (2019) Can the Paris deal boost SDGs achievement? An assessment of climate mitigation co-benefits or side-effects on poverty and inequality. World Dev 122:96. https:// doi.org/10.1016/j.worlddev.2019.05.015

Campbell BM, Hansen J, Rioux J, Stirling CM, Twomlow S, Wollenberg E (2018) Urgent action to combat climate change and its impacts (SDG 13): transforming agriculture and food systems. Curr Opin Environ Sustain 34:12-20. https://doi.org/10.1016/j. cosust.2018.06.005

Cetrulo TB, Marques RC, Malheiros TF, Cetrulo NM (2020) Monitoring inequality in water access: challenges for the 2030 Agenda for Sustainable Development. Sci Total Environ 727:138746. https:// doi.org/10.1016/j.scitotenv.2020.138746

Dhahri S, Omri A (2020) Foreign capital towards SDGs 1 \& 2 ending poverty and hunger: the role of agricultural production. Struct Chang Econ Dyn 53:208-221. https://doi.org/10.1016/j. strueco.2020.02.004

Elavarasan RM, Pugazhendhi R (2020) Restructured society and environment: a review on potential technological strategies to control the COVID-19 pandemic. Sci Total Environ 725:138858. https://doi.org/10.1016/j.scitotenv.2020.138858

Fagbemi F (2021) COVID-19 and sustainable development goals (SDGs): an appraisal of the emanating effects in Nigeria. Res Glob 3:100047. https://doi.org/10.1016/j.resglo.2021.100047

Fenner R, Cernev T (2021) The implications of the Covid-19 pandemic for delivering the Sustainable Development Goals. Futures 128:102726. https://doi.org/10.1016/j.futures.2021. 102726

Forbes (2020) Six places where oceans, rivers and marine life have rebounded during the coronavirus pandemic. https://www. forbes.com/sites/nishandegnarain/2020/05/16/six-places-whereoceans-rivers-and-marine-life-have-rebounded-during-thecoronavirus-pandemic/\#6c662d373fb0 [accessed 1 June 2020]

Fulzele R, Fulzele V, Dharwal M (2021) Mapping the impact of COVID-19 crisis on the progress of Sustainable Development Goals (SDGs) - a focus on global environment and energy efficiencies. Mater Today Proc. https://doi.org/10.1016/j.matpr. 2021.09.517

Giles-Corti B, Lowe M, Arundel J (2019) Achieving the SDGs: evaluating indicators to be used to benchmark and monitor progress towards creating healthy and sustainable cities. Health Policy 124:581. https://doi.org/10.1016/j.healthpol.2019.03.001

GreenBiz (2020) SDG No. 17, coronavirus and the battle for a collaborative future. https://www.greenbiz.com/article/sdg-no-17coronavirus-and-battle-collaborative-future [accessed 21 May 2020]
Hackl A (2018) Mobility equity in a globalized world: reducing inequalities in the sustainable development agenda. World Dev 112:150-162. https://doi.org/10.1016/j.worlddev.2018.08.005

Health TLP (2020) Will the COVID-19 pandemic threaten the SDGs? Lancet Public Health 5:e460. https://doi.org/10.1016/S24682667(20)30189-4

Herrera V (2019) Reconciling global aspirations and local realities: challenges facing the Sustainable Development Goals for water and sanitation. World Dev 118:106-117. https://doi.org/10.1016/j. worlddev.2019.02.009

Herrmanna B, Rundshagen V (2020) Paradigm shift to implement SDG 2 (end hunger): a humanistic management lens on the education of future leaders. Int J Manag Educ 18:100368. https://doi.org/10. 1016/j.ijme.2020.100368

Hughes BB, Hanna T, McNeil K, Bohl DK and Moyer JD (2021) Pursuing the Sustainable Development Goals in a world reshaped by COVID-19. Denver, CO and New York, NY: Frederick S. Pardee Center for International Futures and United Nations Development Programme

International Finance Corporation (2020) The impact of COVID-19 on water and sanitation. https://www.ifc.org/wps/wcm/connect/ industry_ext_content/ifc_external_corporate_site/infrastructure/ resources/the+impact+of+covid-19+on+water+and+sanitation [accessed 3 December 2020]

International Labor Organization (2020) Impact on workers of COVID19 is 'catastrophic': ILO. https://news.un.org/en/story/2020/09/ 1073242 [accessed 5 December 2020]

Internet World Stats (2020) Internet Usage Statistics. https://www.inter networldstats.com/stats.htm [14 May 2020]

IRENA (2020a) Renewable energy statistics 2020. https://www.irena. org/publications/2020/Jul/Renewable-energy-statistics-2020 [accessed 3 December 2020]

IRENA (2020b) IRENA post COVID recovery. https://www.irena. org/publications/2020/Jun/Post-COVID-Recovery. [accessed 7 December 2020]

Jahan Y, Rahman A (2020) COVID-19: Challenges and viewpoints from low-and-middle-income Asian countries perspectives. J Saf Sci Resil 1:70. https://doi.org/10.1016/j.jnlssr.2020.06.012

Jaiswal N, Jayakumar S (2021) Covid-19 Pandemic-changes in the context of global environment and lessons learned. In: Environmental Resilience and Transformation in Times of COVID-19. Elsevier, pp 207-222. https://doi.org/10.1016/B978-0-323-855129.00031-0

Janardhanan N, Mandhyan R, Rawat A, Ikeda E (2021) The COVID-19 impacts on India's low carbon infrastructure. In: Environmental Resilience and Transformation in Times of COVID-19. Elsevier, pp 289-298. https://doi.org/10.1016/B978-0-323-85512-9. 00031-0

Kevin MC, David M, Stephen BR, Christopher S, Derek W (2020) "From the barrel to the pump: the impact of the COVID-19 pandemic on prices for petroleum products," Monthly Labor Review, U.S. Bureau of Labor Statistics, https://doi.org/10.21916/mlr. 2020.24

Khetrapal S, Bhatia R (2020) Impact of COVID-19 pandemic on health system \& Sustainable Development Goal 3. Indian J Med Res 151:395. https://doi.org/10.4103/ijmr.IJMR_1920_20

Kookana RS, Drechsel P, Jamwal P, Vanderzalm J (2020) Urbanisation and emerging economies: Issues and potential solutions for water and food security. Sci Total Environ 732:139057. https://doi.org/ 10.1016/j.scitotenv.2020.139057

Kynclova P, Upadhyaya S, Nice T (2020) Composite index as a measure on achieving Sustainable Development Goal 9 (SDG-9) industry-related targets: the SDG-9 index. Appl Energy 265:114755. https://doi.org/10.1016/j.apenergy.2020.114755

Madurai Elavarasan R, Shafiullah GM, Raju K, Mudgal V, Arif MT, Jamal $\mathrm{T}$ et al (2020) COVID-19: Impact analysis and 
recommendations for power sector operation. Appl Energy 279:115739. https://doi.org/10.1016/j.apenergy.2020.115739

Mallick SK, Pramanik M, Maity B et al (2021) Plastic waste footprint in the context of COVID-19: reduction challenges and policy recommendations towards sustainable development goals. Sci Total Environ 796:148951. https://doi.org/10.1016/j.scitotenv.2021. 148951

Mason-D'Croz D, Sulser TB, Wiebe K, Rosegrant MW, Lowder SK, Nin-Pratt A et al (2019) Agricultural investments and hunger in Africa modeling potential contributions to SDG2 - Zero Hunger. World Dev 116:38. https://doi.org/10.1016/j.worlddev.2018.12. 006

NASA Aura Atmospheric chemistry (2020) Air Quality Observation from space. https://aura.gsfc.nasa.gov/airquality.html [accessed 21 May 2020]

Nundy S, Ghosh A, Mesloub A, Albaqawy GA, Alnaim MM (2021) Impact of COVID-19 pandemic on socio-economic, energy-environment and transport sector globally and sustainable development goal (SDG). J Clean Prod 312:127705. https://doi.org/10. 1016/j.jclepro.2021.127705

Opendatasoft Data Network (2020) World daily spot prices for crude oil WTI and Brent. https://data.opendatasoft.com/explore/datas et/spot-prices-for-crude-oil-and-petroleum-products\%40kapsarc/ table/?sort=europe_brent_spot_price_fob_dollars_per_barrel [accessed 17 May 2020]

Pac J, Garfinkel I, Kaushal N, Nam J, Nolan L, Waldfogel J et al (2020) Reducing poverty among children: evidence from state policy simulations. Child Youth Serv Rev 115:105030. https://doi.org/ 10.1016/j.childyouth.2020.105030

Pinilla-Roncancio M, Mactaggart I, Kuper H, Dionicio C, Naber J, Murthy GVS et al (2020) Multidimensional poverty and disability: a case control study in India, Cameroon, and Guatemala. SSM Popul Health 11:100591. https://doi.org/10.1016/j.ssmph.2020. 100591

pv magazine (2020) Impact of Covid-19 on the global energy sector. https://www.pv-magazine.com/2020/04/24/impact-of-covid-19on-the-global-energy-sector/ [accessed 17 May 2020]

Ranjbari M, Shams Esfandabadi Z, Zanetti MC et al (2021) Three pillars of sustainability in the wake of COVID-19: a systematic review and future research agenda for sustainable development. J Clean Prod 297:126660. https://doi.org/10.1016/j.jclep ro.2021.126660

RMIT (2020) SDG17: Partnerships for the goals. https://www.rmit. edu.au/about/schools-colleges/global-urban-and-social-studies/ research/research-centres-and-groups/european-union-centreof-excellence/projects/eu-role-implementation-sdgs-asiapacific [accessed 26 October 2021]

Schleicher J, Schaafsma M, Vira B (2018) Will the Sustainable Development Goals address the links between poverty and the natural environment? Curr Opin Environ Sustain 34:43. https:// doi.org/10.1016/j.cosust.2018.09.004

Scroll.in (2020) The Covid-19 pandemic has exposed the deep inequality in the US. https://scroll.in/article/960570/the-covid-19pandemic-has-exposed-the-deep-inequality-in-the-us [accessed 16 May 2020]

SDG Compass (2020) The guide for business action on the SDGs. https://sdgcompass.org/ [accessed 1 December 2020]

SDGs Knowledge Platform (2020a) Sustainable Development Goal 1. https://sustainabledevelopment.un.org/sdg1 [accessed 12 May 2020]

SDGs Knowledge Platform (2020b) Sustainable Development Goal 2. https://sustainabledevelopment.un.org/sdg2 [accessed 13 May 2020]

SDGs Knowledge Platform (2020c) Sustainable Development Goal 7. https://sustainabledevelopment.un.org/sdg7 [accessed 16 May 2020]
SDGs Knowledge Platform (2020d) Sustainable Development Goal 12. https://sustainabledevelopment.un.org/sdg12. [accessed 20 May 2020]

SDGs Knowledge Platform (2020e) Sustainable Development Goal 14. https://sustainabledevelopment.un.org/sdg14 [accessed 20 May 2020]

SDGs Knowledge Platform (2020f) Sustainable Development Goal 15. https://sustainabledevelopment.un.org/sdg 15 [accessed 20 May 2020]

Singh V, Mishra V (2021) Environmental impacts of coronavirus disease 2019 (COVID-19). Bioresour Technol Rep 15:100744. https://doi.org/10.1016/j.biteb.2021.100744

Storey M, Killian S, O'Regan P (2017) Responsible management education: mapping the field in the context of the SDGs. Int J Manag Educ 15:93-103. https://doi.org/10.1016/j.ijme.2017. 02.009

Sundewall J, Forsberg BC (2020) Understanding health spending for SDG 3. Lancet 396:650. https://doi.org/10.1016/S0140-6736(20) 30963-6

Sustainable Development Goals (2021) SDG 6. https://www.un.org/ sustainabledevelopment/water-and-sanitation/ [accessed 3 December 2020]

Sustainable Development Report (2021) The decade of action for the Sustainable Development Goals; 2021 [accessed 1 August 2021]

Tayal S, Singh S (2021) Covid-19 and opportunity for integrated management of water-energy-food resources for urban consumption. In: Environmental Resilience and Transformation in Times of COVID-19. Elsevier, pp 135-142. https://doi.org/10.1016/B9780-323-85512-9.00020-6

The Print (2020) India partially lifts ban on export of hydroxychloroquine to help US, others fight Covid-19. https://theprint.in/diplo macy/india-partially-lifts-ban-on-export-of-hydroxychloroquinehours-after-trumps-threat/396792/ [accessed 21 May 2020]

The World Bank (2020) Poverty overview. https://www.worldbank.org/ en/topic/poverty/overview [accessed 13 May 2020]

Tonne C (2021) Lessons from the COVID-19 pandemic for accelerating sustainable development. Environ Res 193:110482. https:// doi.org/10.1016/j.envres.2020.110482

Udmale P, Pal I, Szabo S et al (2020) Global food security in the context of COVID-19: a scenario-based exploratory analysis. Prog Disaster Sci 7:100120. https://doi.org/10.1016/j.pdisas.2020. 100120

UN Environment Programme (2020) Building resilient societies after the covid -19 pandemic, International Resource Panel. https:// www.resourcepanel.org/ [accessed 22 May 2020]

UN SDGs (2020) The Sustainable Development Agenda. https:// www.un.org/sustainabledevelopment/development-agenda-retir ed/ [accessed 12 May 2020]

UN statistics (2020a) SDG 2. https://unstats.un.org/sdgs/report/2020/ goal-02/ [accessed 1 December 2020]

UN Statistics (2020b) SDG 3. https://unstats.un.org/sdgs/report/2020/ goal-03/ [accessed 2 December 2020]

UN statistics (2020c) SDG 8. https://unstats.un.org/sdgs/report/2020/ goal-08/ [accessed 4 December 2020]

UN statistics, 2020d. SDG 9. https://unstats.un.org/sdgs/report/2020/ goal-09/ [accessed 5 December 2020].

UN statistics (2020e) SDG 11. https://unstats.un.org/sdgs/report/2020/ goal-11/ [accessed 6 December 2020]

UN statistics (2020f) SDG 16. https://unstats.un.org/sdgs/report/2020/ goal-16/ [accessed 7 December 2020]

UNDP SDG Integration (2020) Impact of COVID-19 on the sustainable development goals. https://sdgintegration.undp.org/accelerati ng-development-progressduring-covid-19 [accessed 1 December 2020] 
UNDP (2020) A pandemic gives permission for change. https://www. undp.org/content/undp/en/home/blog/2020/a-pandemic-bringspermission-for-change.html [accessed 12 May 2020]

UNESCO Inclusive Policy Lab (2020a) Gender inequality in times of COVID-19 - give women cash. https://en.unesco.org/inclusivep olicylab/news/gender-inequality-times-covid-19-\%E2\%80\%93give-women-cash [15 May 2020]

UNESCO Inclusive Policy Lab (2020b) COVID-19: Inequality is our pre-existing condition. https://en.unesco.org/inclusivepolicylab/ news/covid-19-inequality-our-pre-existing-condition [15 May 2020]

UNESCO (2020a) COVID-19 Educational Disruption and Response. https://en.unesco.org/covid19/educationresponse [accessed 14 May 2020]

UNESCO (2020b) Creative Cities mobilized against Covid-19. https:// en.unesco.org/covid19/cultureresponsecreative-cities-mobilizedagainst-covid-19 [accessed 20 May 2020]

UNESDOC Digital Library (2020) Act now: reduce the impact of COVID-19 on the cost of achieving SDG 4. https://unesdoc.unesco.org/ark:/48223/pf0000374163 [accessed 2 December 2020]

United Nations ESCAP (2020) The Covid-19 pandemic and violence against women in Asia and the Pacific. https://www.unescap.org/ sites/default/files/20201119_SDD_Policy_Paper_Covid-19.pdf [accessed 25 October 2021]

United Nations (2020) Accelerating SDG 7 achievement in the time of COVID-19. https://sustainabledevelopment.un.org/content/docum ents/26235UNFINALFINAL.pdf [accessed 4 December 2020]

Wang Q, Huang R (2021) The impact of COVID-19 pandemic on sustainable development goals - a survey. Environ Res 202:111637. https://doi.org/10.1016/j.envres.2021.111637

Workie E, Mackolil J, Nyika J, Ramadas S (2020) Deciphering the impact of COVID-19 pandemic on food security, agriculture, and livelihoods: a review of the evidence from developing countries.
Curr Res Environ Sustain 2:100014. https://doi.org/10.1016/j. crsust.2020.100014

World Bank Blogs (2020) Hunger amid plenty: How to reduce the impact of COVID-19 on the world's most vulnerable people. https://blogs.worldbank.org/voices/hunger-amid-plenty-howreduce-impact-covid-19-worlds-most-vulnerable-people [accessed 14 May 2020]

World Resources Institute (2020a) Tackling inequality in cities is essential for fighting COVID-19. https://www.wri.org/blog/2020/ 04/coronavirus-inequality-cities [accessed 15 May 2020]

World Resources Institute (2020b) Combating the coronavirus without clean water. https://www.wri.org/blog/2020/04/coronavirus-waterscarcity-hand-washing [accessed 16 May 2020]

World Trade Organization (2020) Trade set to plunge as COVID-19 pandemic upends global economy. https://www.wto.org/english/ news_e/pres20_e/pr855_e.htm [accessed 18 May 2020]

Yunus AP, Masago Y, Hijioka Y (2020) COVID-19 and surface water quality: improved lake water quality during the lockdown. Sci Total Environ 731:139012. https://doi.org/10.1016/j.scitotenv. 2020.139012

Zambrano-Monserrate MA, Ruano MA, Sanchez-Alcalde L (2020) Indirect effects of COVID-19 on the environment. Sci Total Environ 728:138813. https://doi.org/10.1016/j.scitotenv.2020.138813

Zhou X, Moinuddin M (2021) Impacts and implications of the COVID19 crisis and its recovery for achieving sustainable development goals in Asia a review from an SDG interlinkage perspective. In: Environmental Resilience and Transformation in Times of COVID-19. Elsevier, pp 273-288. https://doi.org/10.1016/B9780-323-85512-9.00018-8

Publisher's note Springer Nature remains neutral with regard to jurisdictional claims in published maps and institutional affiliations.

\section{Authors and Affiliations}

\section{Rajvikram Madurai Elavarasan ${ }^{1} \cdot$ Rishi Pugazhendhi ${ }^{2}$ G. M. Shafiullah ${ }^{3} \cdot$ Nallapaneni Manoj Kumar $^{4}$. Mohammad Taufiqul Arif ${ }^{5} \cdot$ Taskin Jamal $^{6}$. Shauhrat Singh Chopra ${ }^{4} \cdot$ Joanna Dyduch $^{7}$}

1 Department of Electrical and Electronics Engineering, Thiagarajar College of Engineering, Madurai 625015, India

2 Research \& Development Division (Power \& Energy), Nestlives Private Limited, Chennai 600091, India

3 Discipline of Engineering and Energy, Murdoch University, Perth, WA 6150, Australia

4 School of Energy and Environment, City University of Hong Kong, Kowloon, Hong Kong, China
5 School of Engineering, Deakin University, Waurn Ponds, Geelong, VIC 3216, Australia

6 Department of Electrical and Electronic Engineering, Ahsanullah University of Science and Technology, Dhaka, Bangladesh

7 The Institute of the Middle and Far East, Jagiellonian University, Oleandry 2a, 30-063 Kraków, Poland 